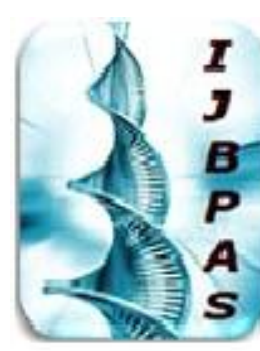

International Journal of Biology, Pharmaey and Allied Sciences (IJBPAS)

'A Bridge Between Caboratory and QRender'

Www.ibpas,com

WORKPLACE VIOLENCE TOWARD EMERGENCY DEPARTMENT

MEDICAL STAFF IN BAGHDAD MEDICAL CITY 2016

HUDA ADNAN HBIB ${ }^{1}$, DR. RAWAIDA A.D. AL-JIBORI ${ }^{2}$, ASEEL SAMIR ${ }^{3}$, LAMIYAA ALI HASAN ${ }^{4}$, ALI ISMAEL KHALIL ${ }^{5}$

1: MBChB, FICMS/F.M/ Professor at Community and Family Medicine Department, Al

Kindy College of Medicine/University of Baghdad

2: MBChB, FICMS/F.M/ MOH

3: PHD / MEDICAL STATISTIC/ Assistant Professor at Community and Family

Medicine Department, Al Kindy College of Medicine/University of Baghdad

4: MBChB, FICMS/F.M/MOH

5: $\mathrm{MBChB}$, C.A.B.P/ $\mathrm{MOH}$

*Corresponding Author: E Mail huda adnan70@yahoo.com; Mobile no.: +9647832028790

Received $15^{\text {th }}$ Aug. 2018; Revised $12^{\text {th }}$ Sept. 2018; Accepted $14^{\text {th }}$ Oct. 2018; Available online $1^{\text {st }}$ Feb. 2019

https://doi.org/10.31032/IJBPAS/2019/8.2.4616

ABSTRACT

Background: The Iraqi hospital witnessed numerous violence incidents against medical staff working in emergency department and range from verbal to physical violence. High frequency of these attacks urged the Iraqi doctors for migration.

Aim of study: To identify the prevalence of workplace violence against medical staff and to and study the risk factors related to work place violence.

Materials and methods: A descriptive cross sectional study carried out among a sample of 300 medical \& paramedical staff in Emergency Department of Baghdad Teaching Hospital in Baghdad Medical city for period from $1^{\text {st }}$ of January to $1^{\text {st }}$ of April, 2016. The data were collected by researcher through distribution of a prepared questionnaire on the eligible participants. The questionnaire was designed by researcher through the experience of previous literatures. 
Results: More than two thirds (76.3\%) of staff was assaulted in last six months; $73.4 \%$ of assaults were verbal and $19.2 \%$ of them were threats. The common frequent reason for assault as perceived by staff was low health education (24.1\%), high number of patients relatives $(23.2 \%)$ and high number of patients $(18 \%)$. The silence was the common reaction of staff toward assault at time and after attack. There was a highly significant association between assault and staff age group of 30-39 years, male gender $(p<0.001)$.

Conclusions: The prevalence of work place violence in emergency department of Baghdad hospitals in last six months is higher than previous literatures.

Keywords: Workplace, violence, assault, emergency department, medical staff, Baghdad INTRODUCTION

The workplace violence (WPV) is defined as any accident or event in which an individual exposed to assault, threats or aggressive act in his workplace ${ }^{[1]}$. It is one of the most interesting and complicated problem facing health stakeholders ${ }^{[2,3]}$. The frequency of WPV against health staff is sixteen times more than other workers. The odds of violence against health care workers are even higher than policemen ${ }^{[4]}$. The WPV is divided into two types; physical and nonphysical (psychological) violence. The physical violence had more destructive effect as it have physical harm and residual psychological harm ${ }^{[5]}$. The physical violence as slugging, booting, smacking, etc. all of which caused by applying physical force against person or peoples, and can cause physical, psychological, or sexual damage ${ }^{[6]}$.
The patients and their relatives are the significant offenders against health care workers [7]; however, the horizontal (staff-to-staff) violence was also reported in literature ${ }^{[8]}$. The main risk factors of violence are patients' characteristics, workplace and/or organizational characteristics and staff characteristics ${ }^{[9]}$. The patients' characteristics which lead to violent behavior are psychiatric health, addiction and patient's anticipations ${ }^{[10]}$. Workplace characteristics involve long waiting times, congestion and poor triage system that always related to violent acts [11], in addition to weak anti-violence policies, bad security and disordered movement system of the public at hospitals ${ }^{[12]}$. Misdistribution of medical staff, nurses' exhaustion, work overload and no previous training are considered as organizational factors ${ }^{[13]}$. The WPV 
prevalence recorded in public hospital to be higher than WPV in private hospitals [14]. The predictors of violence in health institutes related to patient's characteristics are age, gender, staff experience and job title ${ }^{[15]}$.

The pre-hospital emergency medical services (EMS) are frontline services and the significant part of health system. It provides all the time the continuous care to disaster and emergency victims and patients with severe injuries and disease attacks to decrease the mortality and morbidity rates. EMS clients complaining from physical and psychosocial harms are more likely to show aggressive behaviors and unjustified violence ${ }^{[16,17]}$. WPV prevalence against EMS staffs is remarkably high ${ }^{[18]}$. As approved by results of two previous literatures, $80.3 \%$ and $66 \%$ (respectively) of ambulance staff were subjected to assault in last previous year ${ }^{[17,18]}$. The workers in health institutes who are always exposed to irritable and confused patients and their relatives, have high WPV prevalence ${ }^{[19]}$ and facing high risk of occupational hazards, leading to personal, social and organizational outcomes ${ }^{[20]}$, as WPV consequences (physical \& psychological), low health and life quality of staffs ${ }^{[18]}$ in addition to care services quality ${ }^{[21]}$. The common explanations for WPV in emergency department (ED) basic theories of violence include annoyance, society culture, violence level in community, governmental prestige, social and environmental factors ${ }^{[22]}$. Other authors related the WPV to psychological behavior of patients linked to their thought of death and life saving, the national health system effect and implementing organizational regulations and the effect of hospitals administrations [23]

\subsection{Work place violence}

Labor Occupational Safety and Health Administration (OSHA) in United States clarified the workplace violence as "violence or the threat of violence against workers". WPV can be recorded in other areas outside work place and classified to three levels; threats, verbal assault and physical assault or murder. The work place violence is reported during the presence of the employee at his work and the assaulters are grouped into; foreigners, patients, colleagues, and personal relations ${ }^{[24]}$.

The world health organization (WHO) in 2003 defined the WPV in general as 
"events in which the staff are abused, threatened or assaulted in situations linked to their work, including during moving to and from his work, comprising an explicit or obvious and hidden risk to their security, health and life ". The WPV is global horrifying episode nowadays expressed by verbal abuse, threat, physical assault, homicide, bullying, sexual and racial persecution and mental strain $^{[25]}$.

Workplace violence is a serious risk in any occupational workforce setting. Abuse and violence in the healthcare workplace makes the delivery of effective patient care decrease. Violence is a fact of the working life for most nurses. Nursing personnel should be ensured to have the safest work place and be given respectful treatment throughout their shift at the medical facility. According to the National Institute for Occupational Safety and Health, defines workplace violence as "an act of aggression directed toward persons at work or on duty, ranging from offensive or threatening language to homicide" ${ }^{[26]}$.

\subsection{Violence in the Emergency Department}

The emergency department (ED) is an important hospital part facing the dangerous and urgent patient cases and it is considered as mobile settings, affected mainly by sliding risk factors of physical framework, medical staff, patients, relatives and the cultural basics of society [27]. Scarce information is available to define the ED as fertile environment for violence against the medical staff and/or patients $[27,28]$. This is due to many reasons such as most of authors made the WPV in general hospital ${ }^{[28]}$ and psychiatric settings ${ }^{[29]}$. Despite that, many studies were conducted to explore and investigate the causes and risk factors triggering the violence in emergency department of the hospitals and revealed that main variables related to WPV in ED were categorized into environmental, personal and workplace factors ${ }^{[27,30]}$.

\subsubsection{Environmental factors}

The common environmental involve the geographical area of the workplace, the class of patients seeking care in emergency department, addiction prevalence in the society, availability of weapons in community, violence banning laws and extent of their integrity in addition to violence level in society ${ }^{[27]}$. These variables are found to have an effect on violence level in the emergency departments ${ }^{[31]}$. 
The demographic characteristics of the society have been shown to affect significantly the assault frequency in the emergency department ${ }^{31}$. Emergency department of hospitals located within hazardous areas in which high crimes were reported are commonly receiving the violence victims. Drug addiction, bad socioeconomic status, the proliferation of gangs, poverty, large number of arms and simplicity of weapons trade multiplying the probability of violence directed toward medical staff in the emergency department and also outside the emergency department such as private clinics ${ }^{[32]}$. The peoples working in ED and peoples presented to ED are part of their community, so the problems that the society complains are drawn to ED ${ }^{[33]}$.

\subsubsection{Personal factors}

Although the environmental factors had the major effect on violence in the emergency department, other factors also had been reported. The sociodemographic characteristics of medical staff working in $\mathrm{ED}$, their comprehension about outside environment, and interaction within their environment are also important factors [34]. Medical staff age, gender, race, residence and history of previous violence are likely to have effect on workplace violence. In previous American study [35], there were approximately 2.9 million nurses in the United States, of which $94 \%$ were female, $81 \%$ were white, and $51 \%$ had over 20 years of experience. Of these nurses, 117,000 worked in an emergency department setting. The workplace violence literature describes females between the ages of 35 and 55, with ten or more years of experience, as being in the highest risk category for workplace violence $^{[36]}$.

\subsubsection{Workplace factors}

Several researchers suggested that physical design of the emergency department and the culture of the organization were factors contributing to violence ${ }^{[37]}$. Workplace factors included: the physical architecture of the emergency department, organizational infrastructure, policies concerning violence, workplace violence education, and staffing levels ${ }^{[38]}$.

The physical structure of the emergency department influences the occurrence of violence in the workplace ${ }^{[24,27]}$. The architectural design of the emergency department, patient access points, and areas where the staff may be isolated are all part of the physical structure. An 
optimal physical design of an emergency department promotes safety of the staff, patients, and families ${ }^{[24]}$.

\subsection{Violence against doctors in Iraq}

While violence against healthcare workers, as reported by many literatures

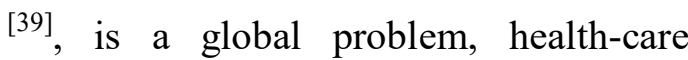
workers in war zones are even more prone to these violent acts with bigger consequences. Many years have passed since the 2003 war in Iraq and the dreams to have a better life never came true. Iraqi doctors are getting assaulted, violated, and humiliated, and as a result, more physicians are leaving the country. More than 2000 doctors have been killed since $2003^{[40]}$. According to Gilbert Burnham and colleagues' study ${ }^{[41]}$, a $22 \%$ decrease has occurred in the number of medical specialists in the capital Baghdad between 2004 and 2007 due in part to violent deaths $(1 \cdot 65 \%)$, threats $(3 \%)$, and kidnappings (0.67\%). In a 2008 survey of emergency department physicians in Iraq, $80 \%$ reported an assault by a patient or a family member, $38 \%$ of which involved a gun threat. Resident physicians were no exception, $87 \%$ reported assault and $86 \%$ reported that it is emotionally painful to talk about their experience ${ }^{[42]}$. These violent assaults were a trigger for many physicians to leave the country ${ }^{[44]}$. In war-torn Iraq, these assaults might result from bereavement, lack of security, internal political corruption, and inadequate repartition of physicians. If this phenomenon continues, more doctors will be forced to leave the country and the health of the population will continue to deteriorate ${ }^{[41-43]}$.

In previous Iraqi cross sectional study conducted in emergency department of Basra hospitals which collected the responses of medical and paramedical staff and found that "verbal violence/ intimidation is the most common, followed by physical violence, and the least frequent is hospital-property damage/ theft associated with violence and the rates lie in the middle of international range ${ }^{[44]}$. Violence, which worries the victims most, usually occurs during the daytime work shifts and the main perpetrator is a male, who is mostly the patient's family member, relative, companion or friend. Workplace violence victims either do nothing as an immediate response to the incident or take limited actions and they, often, do not take an action after the end of the incidents. Furthermore, violence does not leave 
long -term consequences in Iraqi professionals" [45].

\section{Aims of study}

1. To evaluate of emergency care workers perception toward work place violence.

2. To find out work place violence risk factors.

3. To find out the work place violence impact on emergency care workers satisfaction.

\section{MATERIALS AND METHODS}

\section{Study design \& settings}

A descriptive cross sectional study carried out in Emergency Department (ED) of Baghdad Teaching Hospital in Baghdad Medical city for period from $1^{\text {st }}$ of January to $1^{\text {st }}$ of April, 2016.

\section{Population of the study}

All health care workers (medical \& paramedical) in Emergency Department (ED) of Baghdad Teaching Hospital in Baghdad Medical city were the study population.

\section{Inclusion criteria}

1. Medical and paramedical staff.

2. Carrier duration more than 6 months.

\section{Exclusion criteria}

1. Refuse to participate.

2. Other workers in ED.

\section{Sampling}

A convenient sample of 300 medical \& paramedical staff in Emergency Department (ED) of Baghdad Teaching Hospital in Baghdad Medical city was taken after their approval to participate in the study.

\section{Data collection}

The data were collected by researcher through distribution of a prepared questionnaire on the eligible participants. The questionnaire included in its first paper a full explanation of the study objectives and the correct way to answer.

The questionnaire included the followings:

1) Demographic characteristics: Age, gender and residence.

2) Job characteristics: Job title, carrier duration and job residence.

3) Violence history: assault in last 6 months, type, assaulter type and history of injury.

4) Reasons for violence in ED.

5) Response of medical staff at time of attack and after that.

6) Response of colleagues.

7) Response of security men in ED.

8) History of reporting and reasons for not reporting.

9) Response of hospital administration. 
10) Response of Ministry of Health.

11) Response of doctors' syndicate.

12) Response of media.

13) Response of Iraqi Parliament.

14) Reaction of medical staff for future assault.

15) Participant's recommendations for preventing workplace violence in ED.

\section{Statistical analysis}

All patients' data entered using computerized statistical software; Statistical Package for Social Sciences (SPSS) version 22 was used. Descriptive statistics presented as (mean \pm standard deviation) and frequencies as percentages. Kolmogorov Smirnov analysis verified the normality of the data set. Chi square test was used for comparison between categorical data. In all statistical analysis, level of significance ( $p$ value) set at $\leq 0.05$. Statistical analysis of the study was done by the community medicine specialist.

\section{RESULTS}

A total of 300 emergency medical staff (EMS) were included in this study with mean age of $33 \pm 6$ years; $57.3 \%$ of them were in age group 30-39 years. Males were more than females with male to female ratio as 1.5:1. Baghdad EMS residents constituted $72.3 \%$ and $27.7 \%$ of them were outside Baghdad residents. All these findings were shown in table 1 and figures 1,2 .

More than half of EMS (56\%) was permanent doctors, $16 \%$ resident doctors, $15 \%$, specialists, $7.3 \%$ nurses, $3 \%$ general practitioner doctors and $0.7 \%$ radiology assistants. Mean experience duration of EMS was $8.3 \pm 5.9$ years; $74 \%$ of them had career duration of more than 5 years. The job residence was emergency for $51.7 \%$ of EMS, Ward for $30 \%$ of them, consultancy clinic for $17.3 \%$ and administrative for $1 \%$ of them. Most of EMS was working in morning and night shifts. All these findings were shown in table 2 and figures 3,4 .

More than two thirds $(76.3 \%)$ of EMS was assaulted in last six months; $73.4 \%$ of assaults were verbal and $19.2 \%$ of them were threats. Threats were transmitted in $62.2 \%$ of cases by other persons and $24.5 \%$ were by weapons. In most of cases assaults occurred in more than time. The assault was mainly done by patients' relatives (66.9\%), security men $(19.2 \%)$, patient $\&$ relatives $(5.6 \%)$, patients $(4.1 \%)$, EMS colleague $(2.7 \%)$ and EMS manager (1.5\%). Most of EMS did not have injury from assault and 
$10.5 \%$ of them were injured by assault. All these findings were shown in table 3 and figures 5-7.

The common frequent reason for assault as perceived by EMS was low health education (24.1\%), high number of patients' relatives $(23.2 \%)$, high number of patients $(18 \%)$, absence of medical facilities (15.1\%), low response of EMS $(6.6 \%)$, patient death $(5.1 \%)$, deteriorated health of patients (4.7\%) and low response of doctors (3.2\%). All these findings were shown in table 4 and figure 8.

The silence was the reaction of $43.2 \%$ of EMS toward assault at time of attack and $25.6 \%$ of them asked assaulter to stop their attack. Upset was the reaction of $38.3 \%$ of EMS toward assault after attack, $23.3 \%$ of them thought about migration and $20.3 \%$ of them wanted to leave work. All these findings were shown in table 5 .

More than half (56\%) of EMS colleagues defend about them and $31.6 \%$ of the colleagues ignore assaulted EMS. The silence was the reaction of $64.7 \%$ of EMS relatives after assault and $27.4 \%$ of them were not informed. Most of security men working in emergency department ignore the assault. Less than half (42.8\%) of EMS informed the hospital administration after the assault and $57.2 \%$ of them did not inform; $81.6 \%$ of those who did not inform thought that it is useless. All these findings were shown in table 6 and figures 9, 10 .

More than two thirds of assaults (73.7\%) were ignored by hospitals administrations and punishing medical staff in $7.9 \%$ of cases. Most of these assaults were neglected by ministry of health $(\mathrm{MOH})$ and manipulation of legislations in $2.3 \%$ of cases. The doctors' syndicate had no reaction in $62.3 \%$ of assaults, denounce \& condemn in $32.8 \%$ and legal chase in $2.3 \%$ of assaults. The media had no reaction in $75.6 \%$ of assaults, triggering the problem in $15.4 \%$ of assaults and denounce in $7.1 \%$ while public education was only in $1.9 \%$ of assaults. The majority of assaults were neglected by parliament and in 3\% of cases there was legislation. All these findings were shown in table 7.

Less than half $(40.6 \%)$ of EMS was forced to waive their legal complaint; $48.1 \%$ of them were forced by hospital administration and $17.6 \%$ of them were forced by tribe. The EMS reaction for future assault was migration (47.3\%), none $(27.7 \%)$, complaint to high officials 
$(11.7 \%)$, resign $(11.7 \%)$, vacation $(1.1 \%)$ and change spatiality $(0.4 \%)$. All these findings were shown in table 8 and figure 11.

The recommendations of EMS toward workplace violence in ED were; Activation of doctor protection legislations and laws (15.1\%), Decreasing patients relatives (14.8\%), Re-enforce security procedures (14.4\%), Media participation in increasing public awareness on doctor role and significance $(14.3 \%)$, Increase human resources in each department (13.7\%), Lowering working duration (12.8\%), Training workshops in communication with patients (12\%), Apply regular shift works $(10.3 \%)$ and other suggestions (6.5\%); the common other suggestions were new legislation of doctors protection, changing national health system and punishing security forces for their ignorance. All these findings were shown in table 9 and figure 12, 13.
There was a highly significant association between assault and EMS age group of 40-49 years $(\mathrm{p}<0.001) . \quad$ A highly significant association was observed between male staff and assault $(\mathrm{p}<0.001)$. No significant differences between assaulted and not assaulted EMS regarding their residence $(p=0.4)$. All these findings were shown in table 10 and figure 14, 15.

As shown in table 11 and figure 16, no significant differences between assaulted and not assaulted EMS regarding their work schedule $(p=0.2)$. A significant association was observed between each of nurses and radiology assistant job title with assault $(p=0.006)$. There was a significant association between consultancy clinic job residence and assault $(p=0.01)$. EMS with long duration carrier were significantly associated with assault ( $\mathrm{p}=0.03)$.

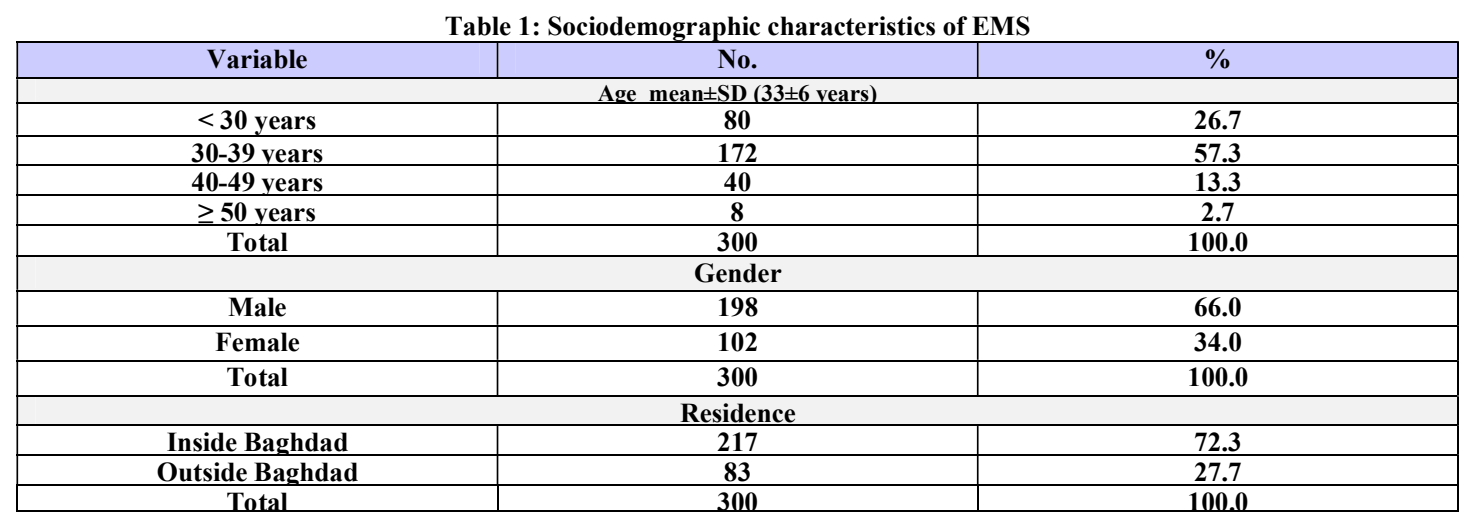




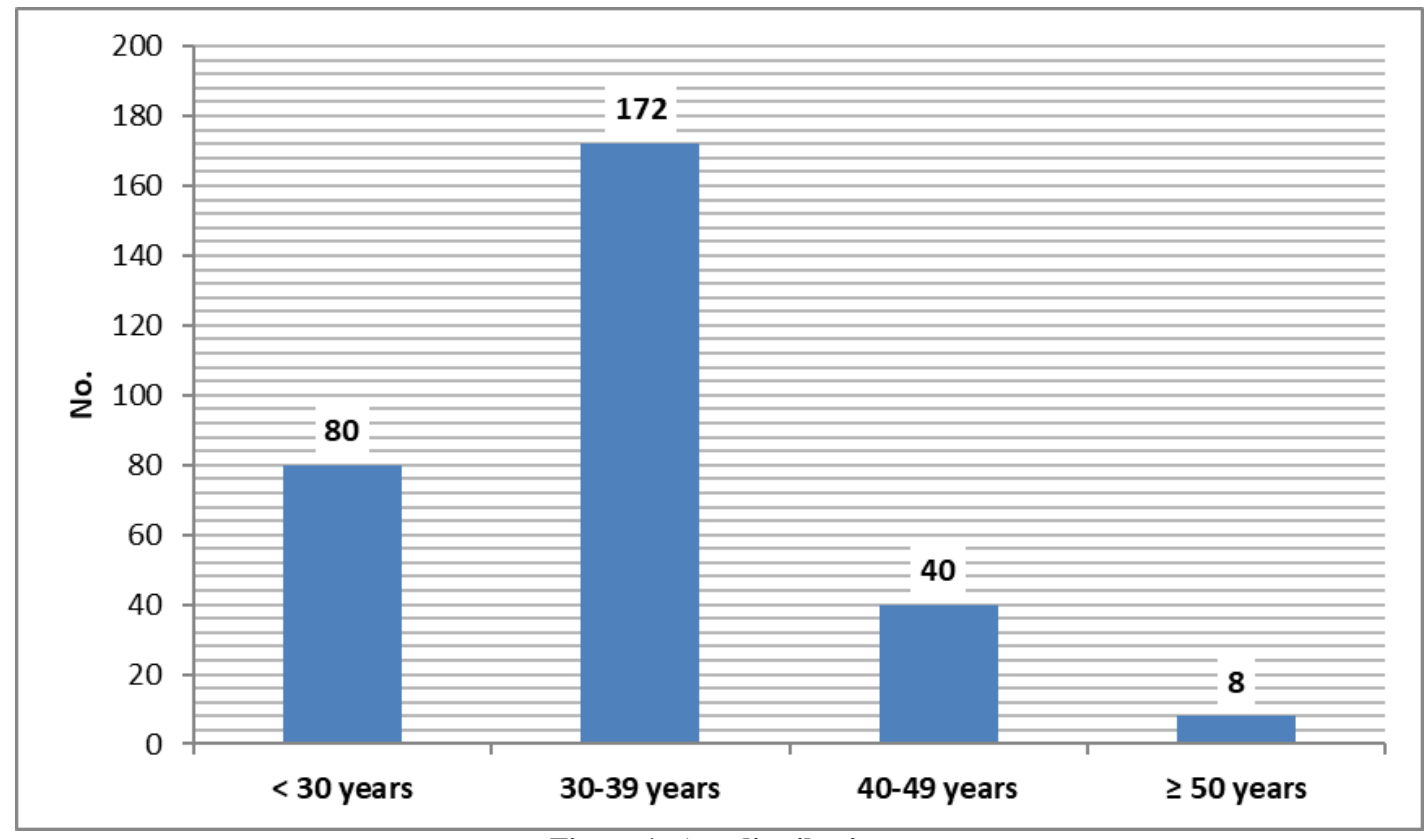

Figure 1: Age distribution

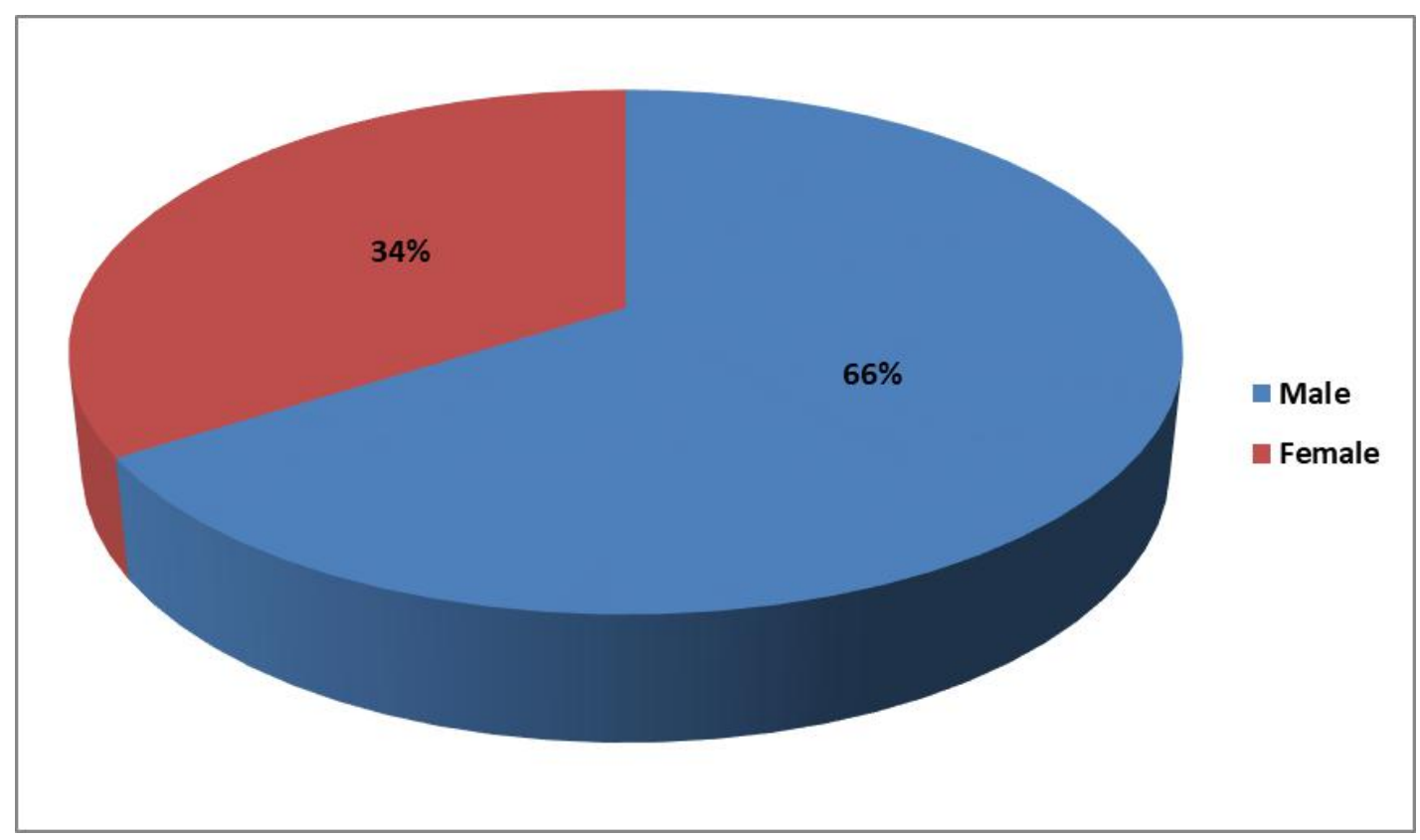

Figure 2: Gender distribution 
Table 2: Job characteristics of EMS

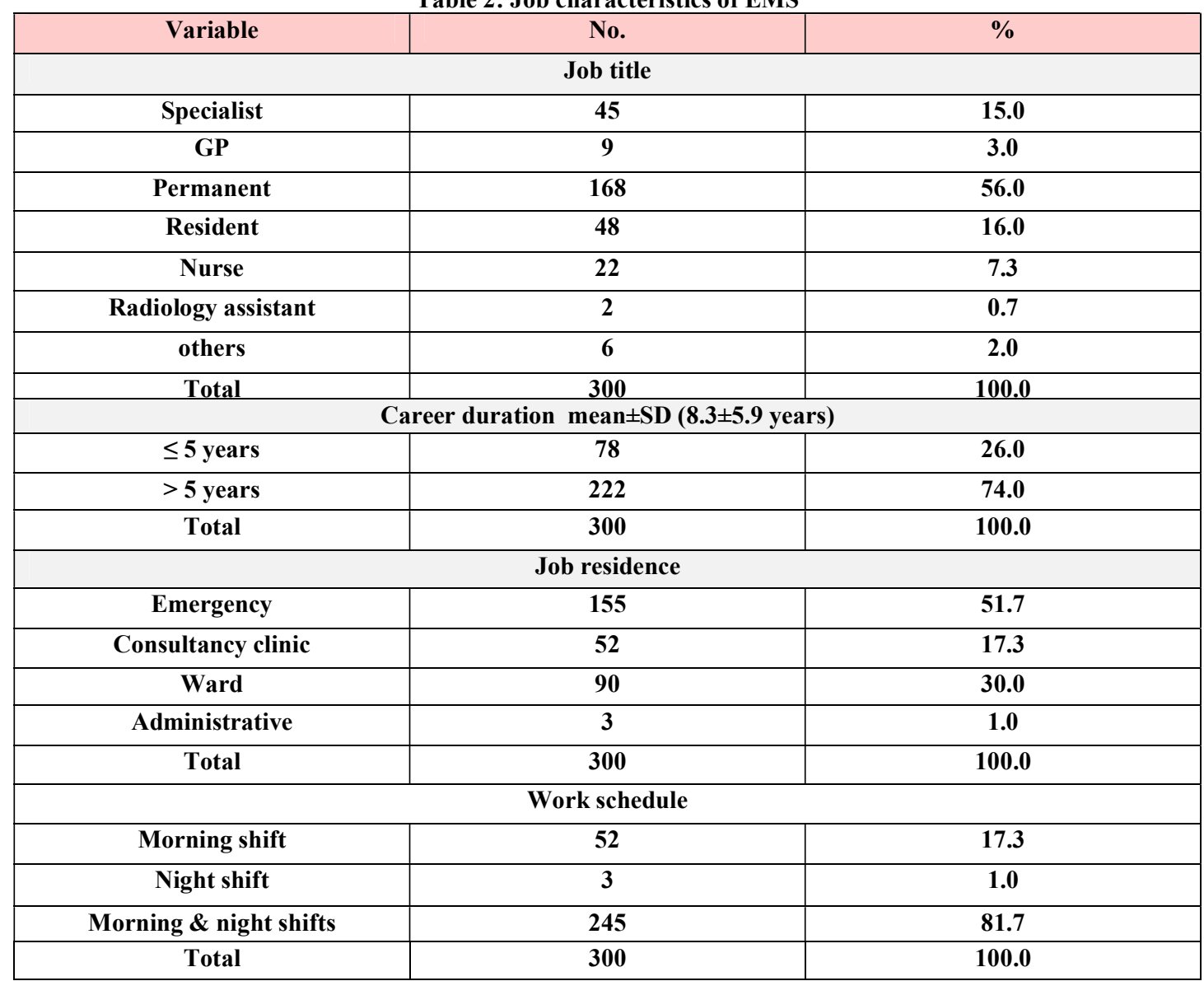

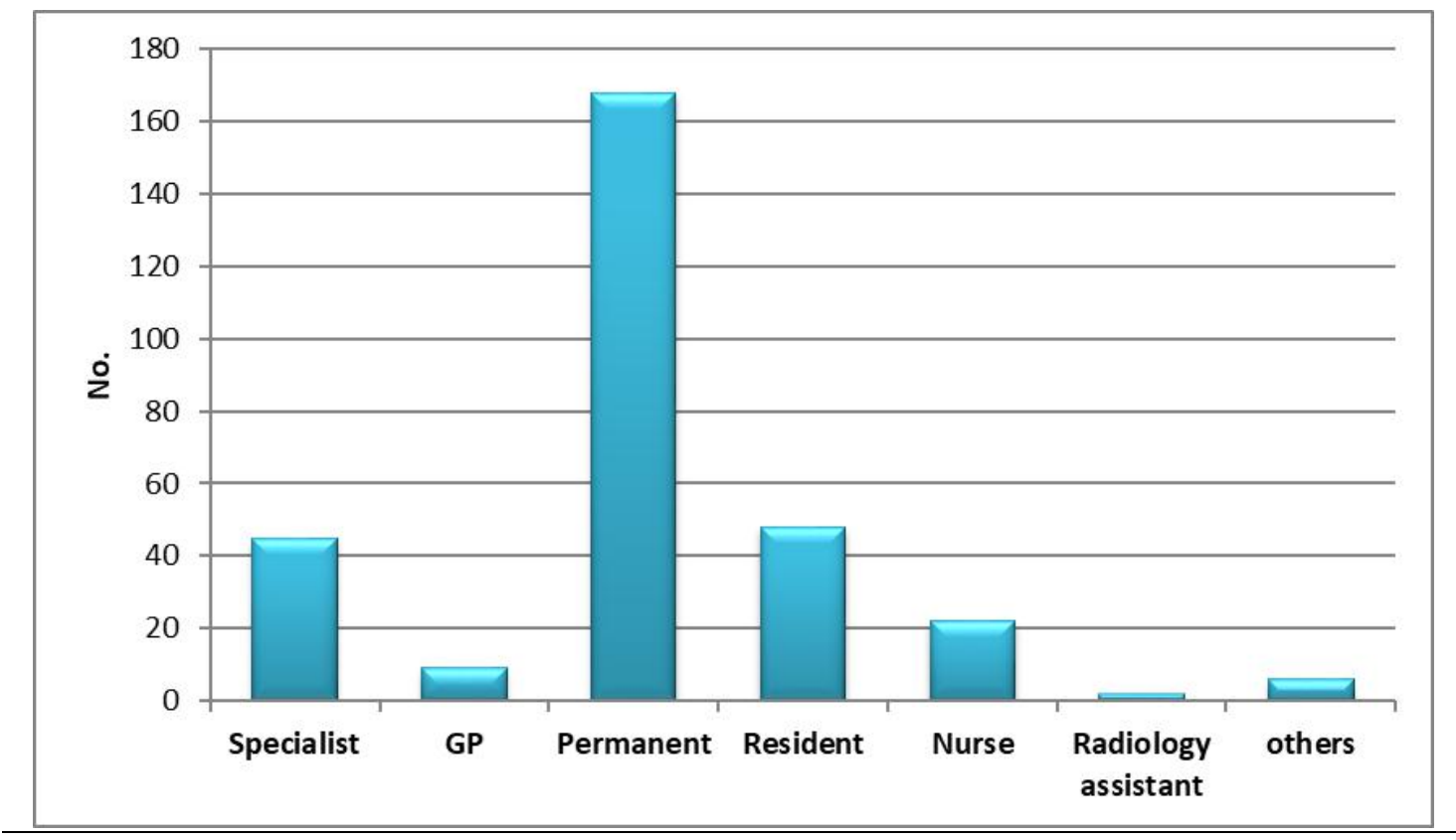

Figure 3: EMS job title 


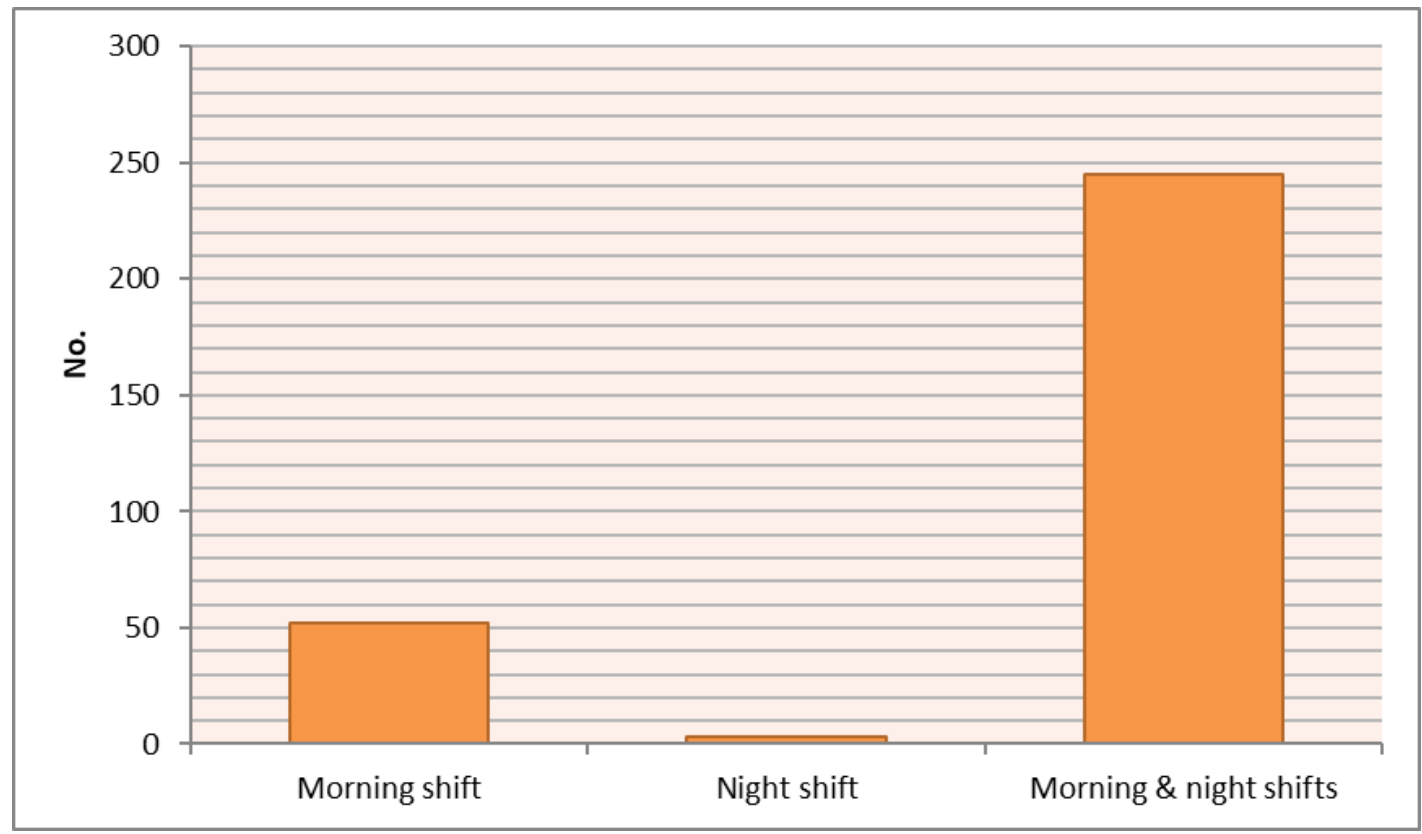

Figure 4: EMS work schedule

Table 3: Distribution of assault toward EMS

\begin{tabular}{|c|c|c|}
\hline & & \\
\hline Variable & No. & $\%$ \\
\hline \multicolumn{3}{|c|}{ Assault in last six months } \\
\hline Yes & 229 & 76.3 \\
\hline No & 71 & 23.7 \\
\hline Total & 300 & 100.0 \\
\hline \multicolumn{3}{|c|}{ Assault type } \\
\hline Verbal & 168 & 73.4 \\
\hline Physical & 17 & 7.4 \\
\hline Threat & 444 & 19.2 \\
\hline Total & 229 & 100.0 \\
\hline \multicolumn{3}{|c|}{ Threat type } \\
\hline Message & 6 & 13.3 \\
\hline Weapons & 11 & 24.5 \\
\hline Other persons & 28 & 62.2 \\
\hline Total & 45 & 100.0 \\
\hline \multicolumn{3}{|c|}{ Assault frequency } \\
\hline One time & 30 & 11.3 \\
\hline More than one time & 236 & 88.7 \\
\hline Total & 266 & 100.0 \\
\hline \multicolumn{3}{|c|}{ Assaulter type } \\
\hline Patient & 11 & 4.1 \\
\hline Relative & 178 & 66.9 \\
\hline Colleague & 7 & 2.7 \\
\hline Manager & 4 & 1.5 \\
\hline Security & 51 & 19.2 \\
\hline
\end{tabular}




\begin{tabular}{|c|c|c|}
\hline Patients \& relatives & 15 & 5.6 \\
\hline Total & 266 & 100.0 \\
\hline \multicolumn{3}{|c|}{ Did you have injury } \\
\hline Yes & 28 & 10.5 \\
\hline No & 238 & 89.5 \\
\hline Total & 266 & 100.0 \\
\hline
\end{tabular}

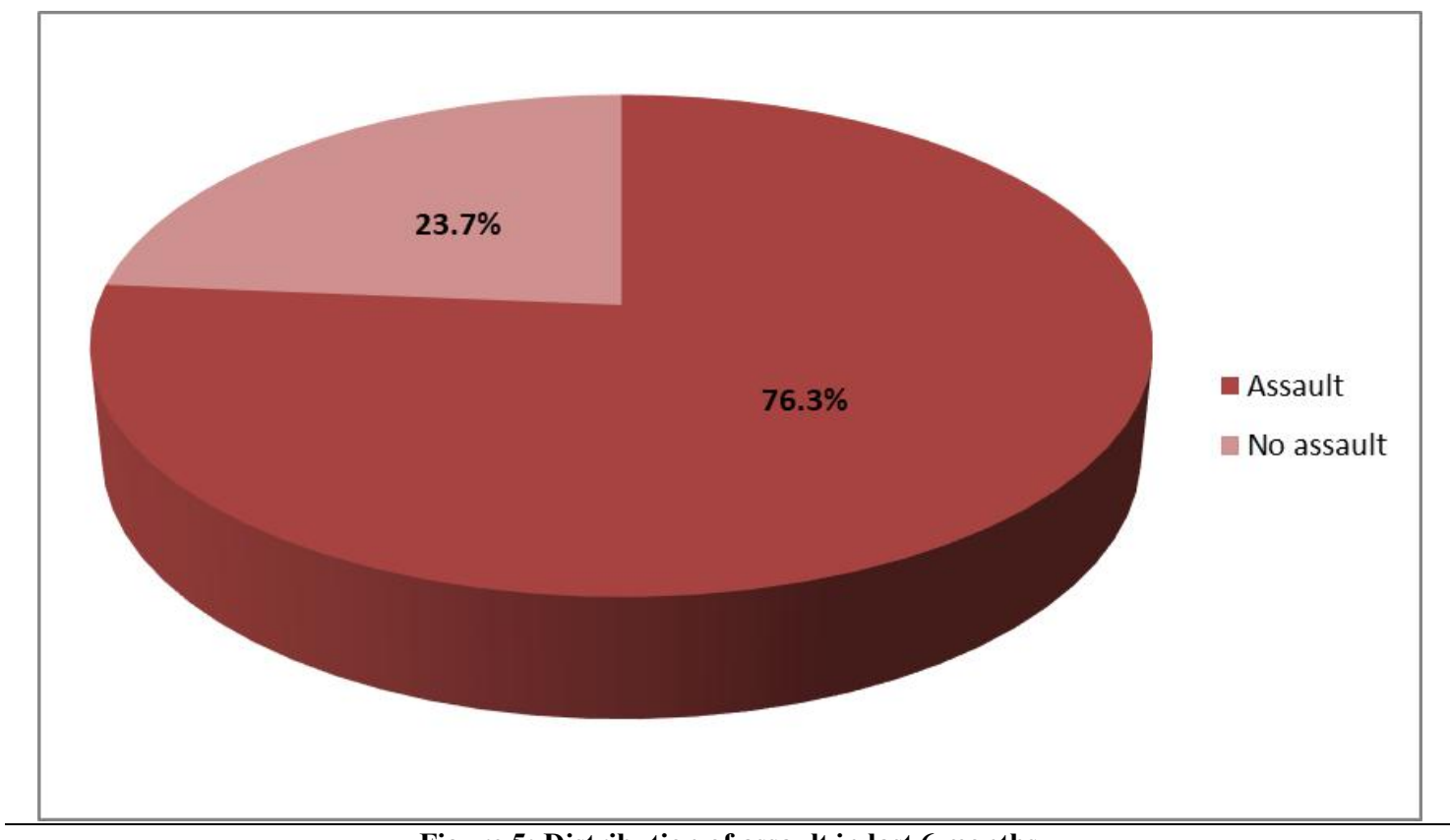

Figure 5: Distribution of assault in last 6 months

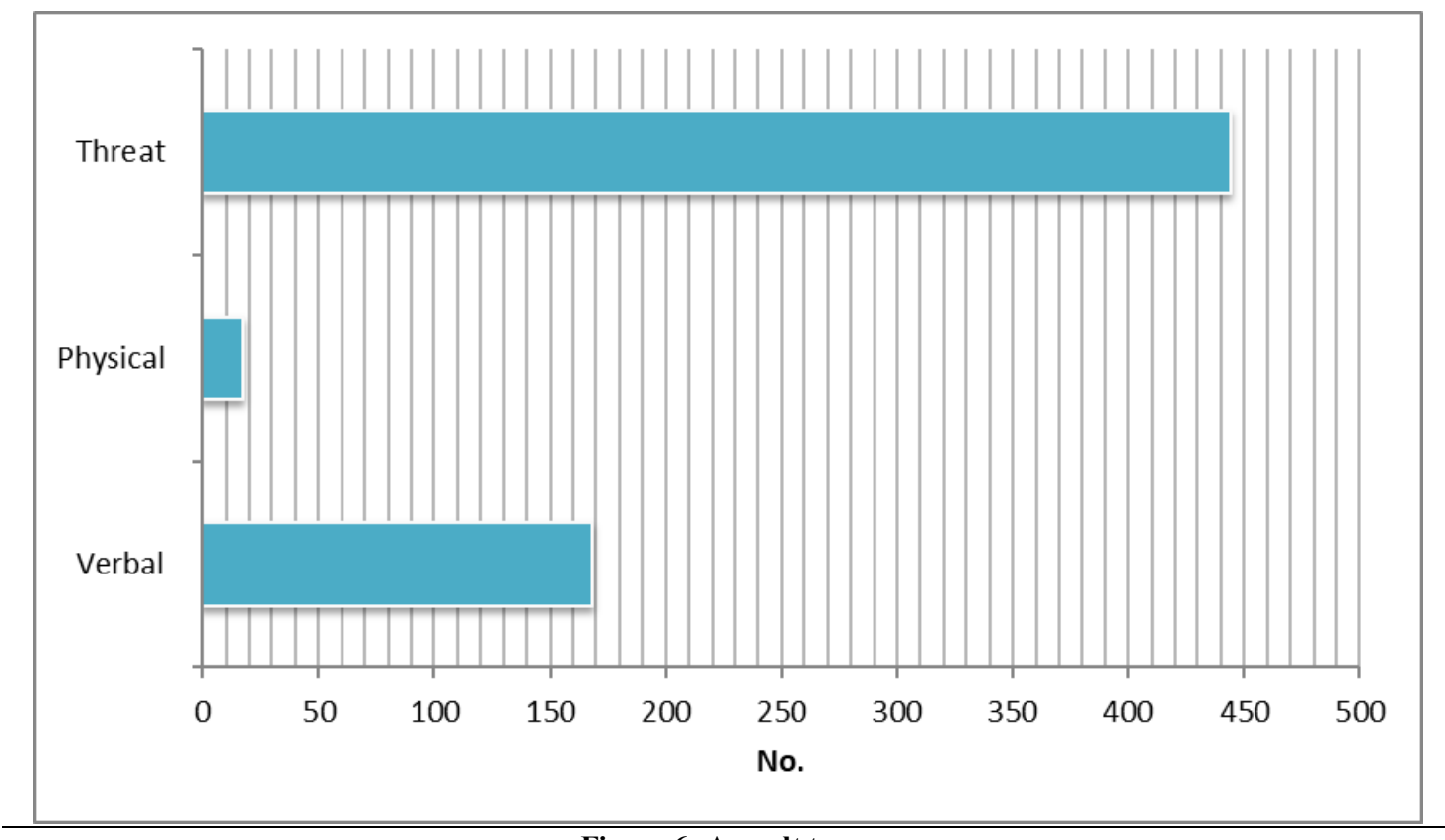

Figure 6: Assault types

IJBPAS, February, 2019, 8(2) 


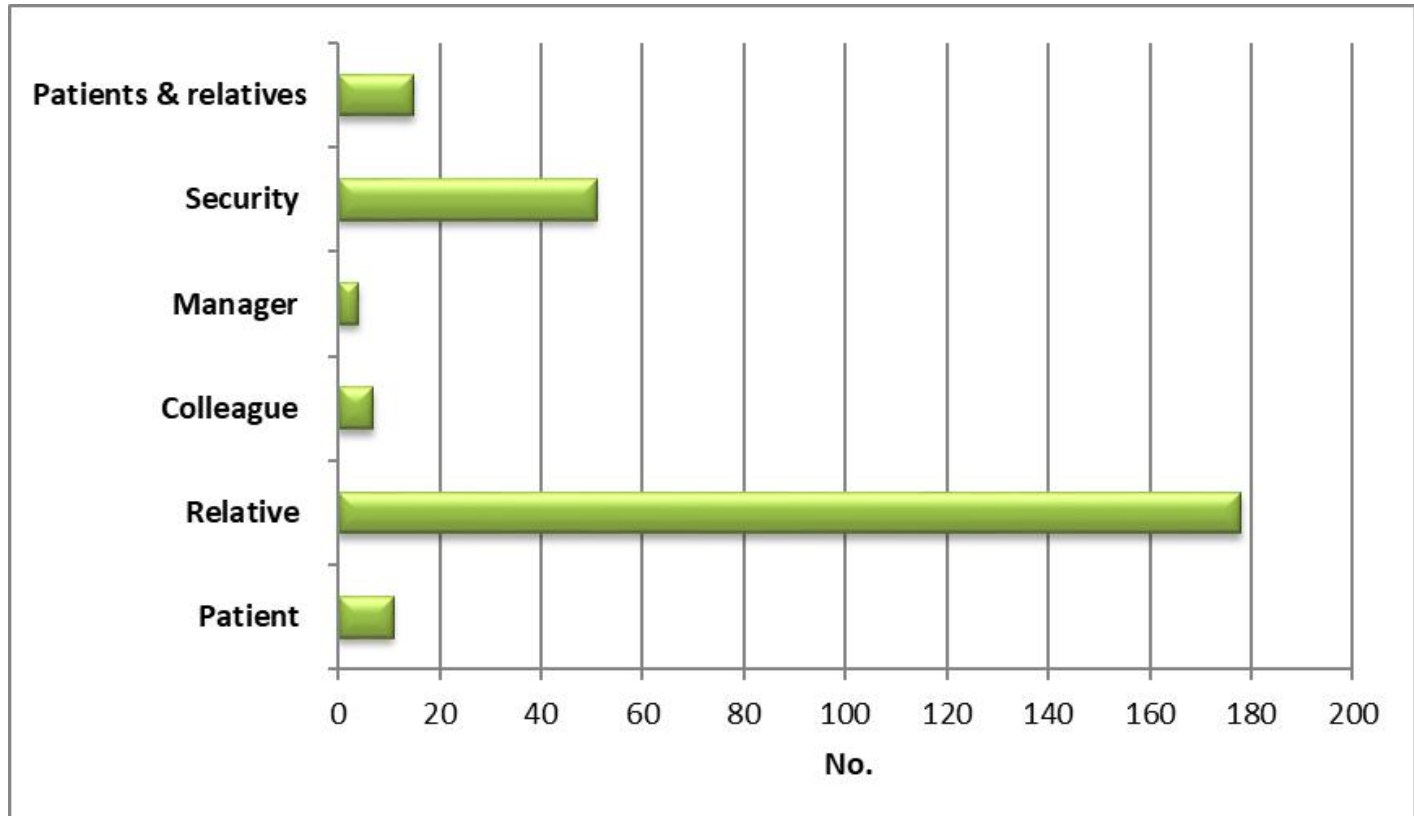

Figure 7: Assaulter types

\begin{tabular}{|c|c|c|}
\hline Variable & No. & $\%$ \\
\hline \multicolumn{3}{|c|}{ Reasons for assault as perceived by medical staff } \\
\hline Low response of medical staff & & \\
\hline & 62 & 6.6 \\
\hline Low response of doctors & 30 & 3.2 \\
\hline High number of patients & 169 & 18.0 \\
\hline High number of relatives & 218 & 23.2 \\
\hline Deteriorated health status of pati & 44 & 4.7 \\
\hline Low health education & 227 & 24.1 \\
\hline Patient death & 48 & 5.1 \\
\hline Absence of medical facilities & 142 & 15.1 \\
\hline Total & 940 & 100.0 \\
\hline
\end{tabular}




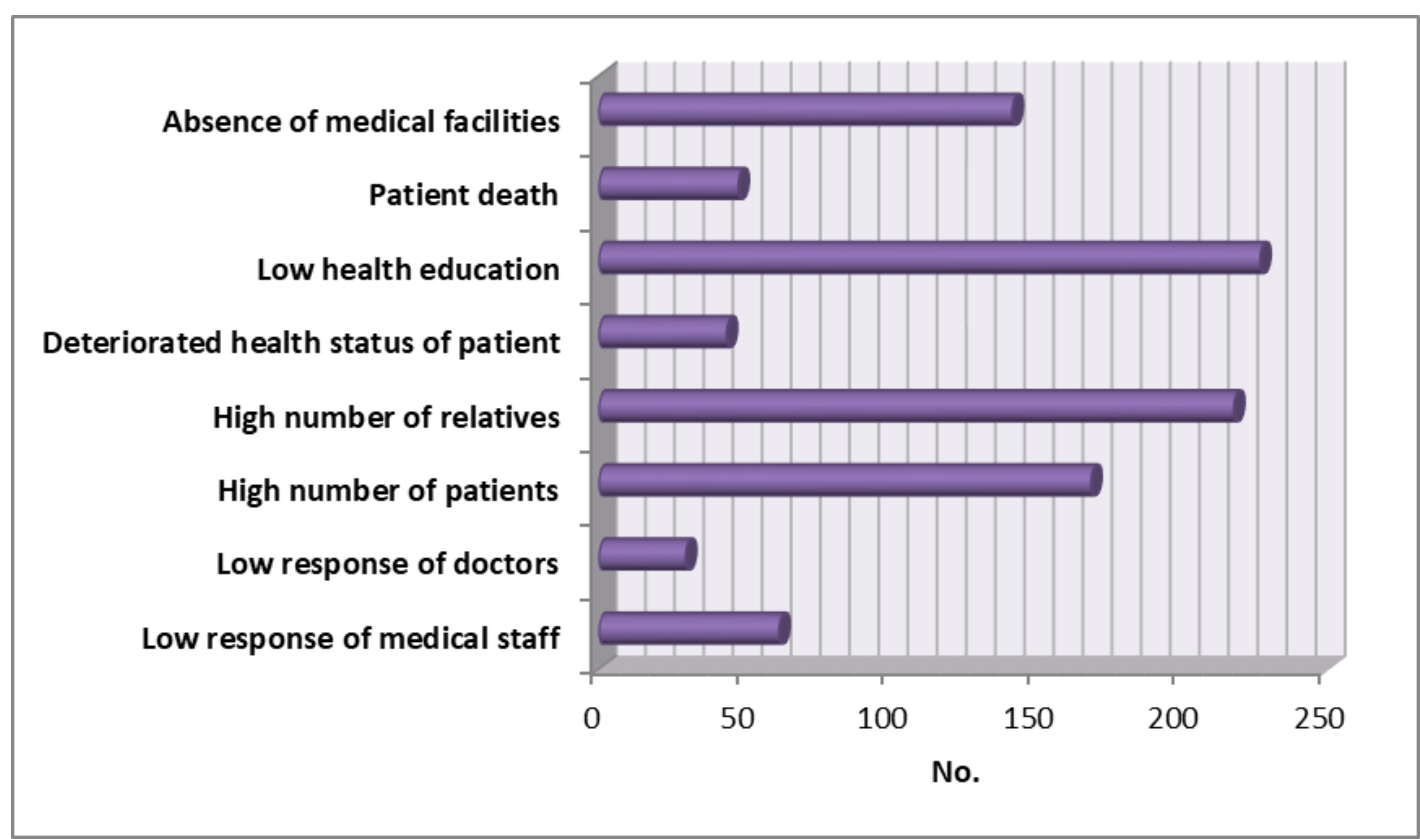

Figure 8: Reasons for assault.

Table 5: Reaction of EMS toward assault

\begin{tabular}{|c|c|c|}
\hline Variable & No. & \multicolumn{2}{c|}{$\%$} \\
\hline Silence & 115 & 23.2 \\
\hline Asked to stop & 68 & 1.9 \\
\hline Inform family & 5 & 6.8 \\
\hline Teaction of medical staff toward assault at time of attack & 13.2 \\
\hline Formal complaint to hospital & 18 & 6.8 \\
\hline Formal complaint to police & 35 & 2.6 \\
\hline Formal complaint to hospital and police & 18 & 100.0 \\
\hline Total & 7 & 38.3 \\
\hline Upset but ignore it & 266 & 6.0 \\
\hline Wanted to change workplace in same hospital & 102 & 7.9 \\
\hline Wanted to change the hospital or institute & 16 & 20.3 \\
\hline Wanted to leave work & 21 & 2.3 \\
\hline Wanted a vacation & 54 & 0.8 \\
\hline Change specialty & 6 & 23.3 \\
\hline Migration & 2 & 1.1 \\
\hline Legal chase & 62 & 100.0 \\
\hline Total & 266 & \\
\hline
\end{tabular}


Table 6: Reactions of colleagues, relatives and security toward assault

\begin{tabular}{|c|c|c|}
\hline Variable & No. & $\%$ \\
\hline \multicolumn{3}{|c|}{ Reaction of colleagues } \\
\hline Defense about you & 149 & 56.0 \\
\hline Leave place & 22 & 8.3 \\
\hline Ignorance & 84 & 31.6 \\
\hline Participate in assault & 11 & 4.1 \\
\hline Total & 266 & 100.0 \\
\hline \multicolumn{3}{|c|}{ Reaction of medical staff relatives } \\
\hline Silence & 172 & 64.7 \\
\hline Formal complaint & 21 & 7.9 \\
\hline Not informed & 73 & 27.4 \\
\hline Total & 266 & 100.0 \\
\hline \multicolumn{3}{|c|}{ Security men reaction } \\
\hline Ignorance & 231 & 86.8 \\
\hline Interfere and stop assaulter & 35 & 13.2 \\
\hline Total & 266 & 100.0 \\
\hline \multicolumn{3}{|c|}{ Did you inform hospital administration? } \\
\hline Yes & 114 & 42.8 \\
\hline No & 152 & 57.2 \\
\hline Total & 266 & 100.0 \\
\hline \multicolumn{3}{|c|}{ If no, why? } \\
\hline Not important & 7 & 4.6 \\
\hline Useless & 124 & 81.6 \\
\hline No one to inform & 3 & 2.0 \\
\hline Fear of bad sequale & 10 & 6.6 \\
\hline Shame & 6 & 3.9 \\
\hline Others & 2 & 1.3 \\
\hline Total & 152 & 100.0 \\
\hline
\end{tabular}




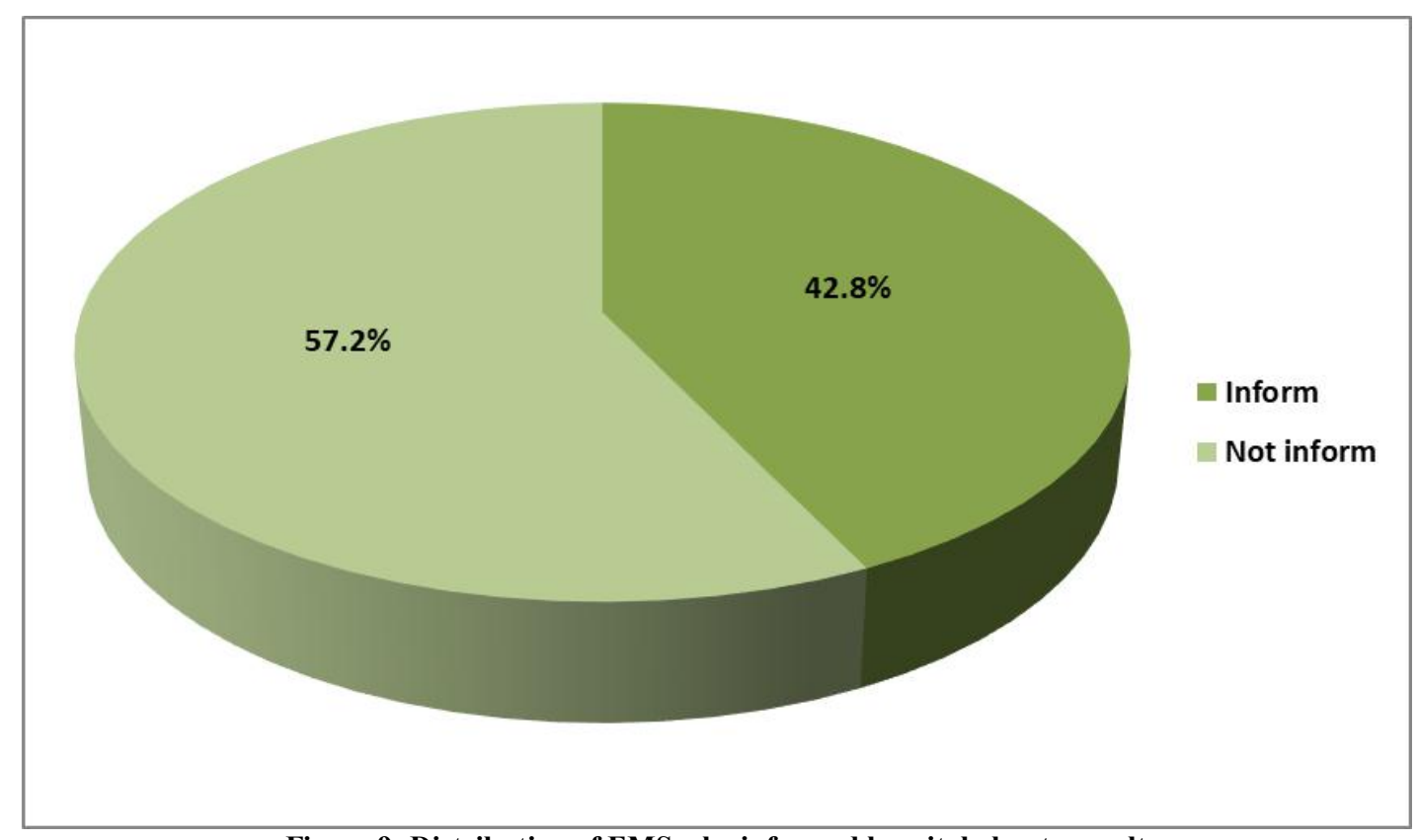

Figure 9: Distribution of EMS who informed hospital about assault

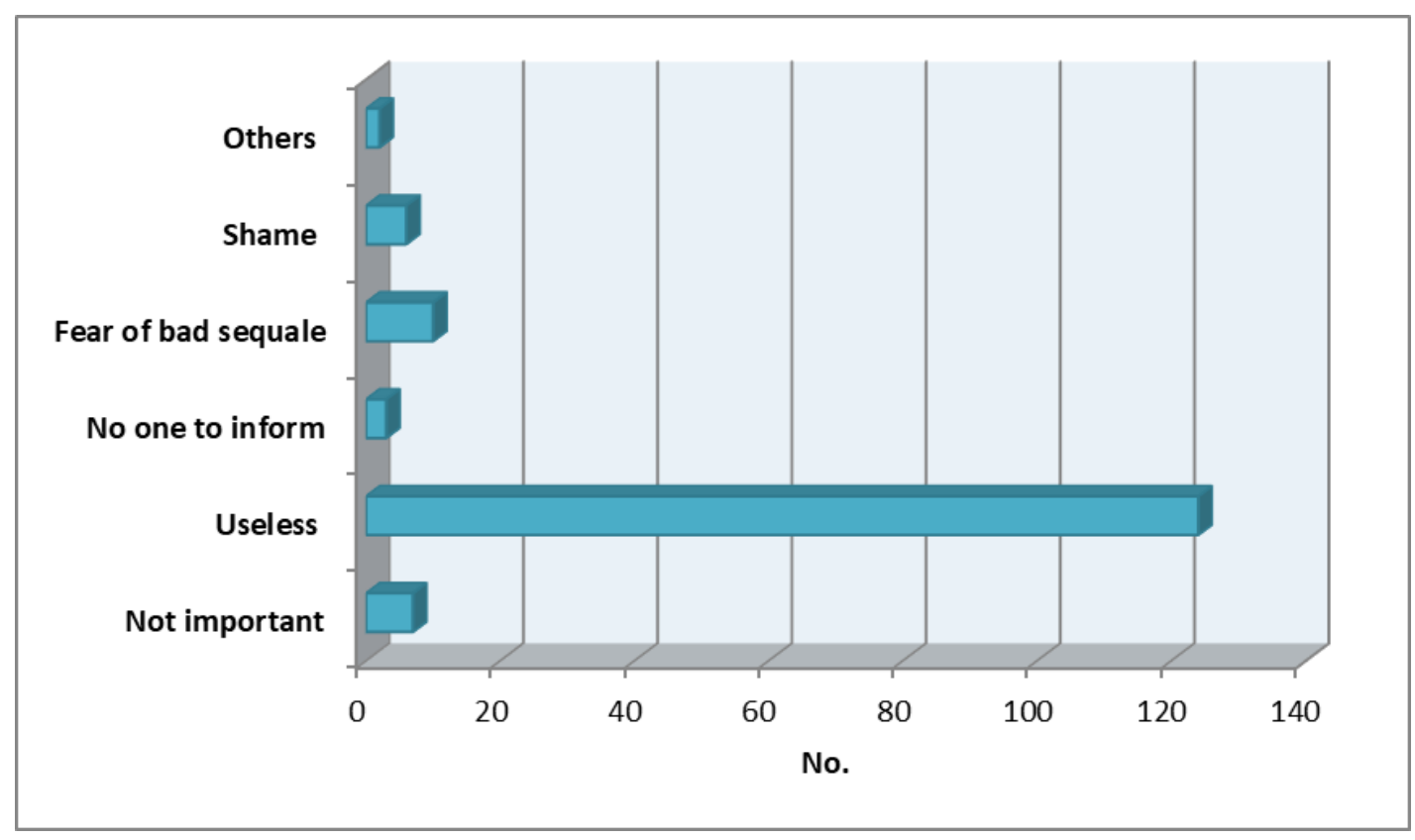

Figure 10: EMS reasons for not informing 
Table 7: Reaction of hospital, MOH, syndicate, media and parliament

\begin{tabular}{|c|c|c|}
\hline Variable & No. & $\%$ \\
\hline \multicolumn{3}{|c|}{ Reaction of hospital administration } \\
\hline Beside the assaulted & 21 & 18.4 \\
\hline Ignorance & 84 & 73.7 \\
\hline Punishing medical staff & 9 & 7.9 \\
\hline Total & 114 & 100.0 \\
\hline \multicolumn{3}{|c|}{ Reaction of MOH } \\
\hline None & 249 & 93.6 \\
\hline Investigation committee & 9 & 3.4 \\
\hline Manipulation of legislations & 6 & 2.3 \\
\hline Investigation papers & 2 & 0.7 \\
\hline Total & 266 & 100.0 \\
\hline \multicolumn{3}{|c|}{ Reaction of doctors syndicate } \\
\hline None & 165 & 62.3 \\
\hline Denounce and condemn & 87 & 32.8 \\
\hline Legal chase & 6 & 2.3 \\
\hline Protests & 4 & 1.3 \\
\hline Strikes & 4 & 1.3 \\
\hline Total & 266 & 100.0 \\
\hline \multicolumn{3}{|c|}{ Reaction of media } \\
\hline None & 201 & 75.6 \\
\hline Public education & 5 & 1.9 \\
\hline Denounce & 19 & 7.1 \\
\hline Triggering the problem & 41 & 15.4 \\
\hline Total & 266 & 100.0 \\
\hline \multicolumn{3}{|c|}{ Reaction of parliament } \\
\hline None & 255 & 95.9 \\
\hline Denounce & 2 & 0.8 \\
\hline Legislation & 8 & 3.0 \\
\hline Conference & 1 & 0.4 \\
\hline Total & 266 & 100.0 \\
\hline
\end{tabular}

Table 8: EMS forcing to waive and their reaction to future assault

Table 8: EMS forcing to waive and their reaction to future assault
\begin{tabular}{|c|c|c|}
\hline Variable & No. & $\%$ \\
\hline \multicolumn{2}{|c|}{ Did you forced to waive legal complaint? } \\
\hline Yes & 108 & 40.6 \\
\hline No & 158 & 59.4 \\
\hline Total & 114 & 100.0 \\
\hline Hospital administration & If yes, by who? & 48.1 \\
\hline Police & 52 & 13.0 \\
\hline Relative & 14 & 5.6 \\
\hline Tribe & 6 & 17.6 \\
\hline Others & 19 & 15.7 \\
\hline
\end{tabular}




\begin{tabular}{|c|c|c|}
\hline Total & 108 & 100.0 \\
\hline \multicolumn{2}{|c|}{ Reaction for future assault } \\
\hline None & 73 & 27.7 \\
\hline Vacation & 3 & 1.1 \\
\hline Complaint to high officials & 31 & 11.7 \\
\hline Change specialty & 1 & 0.4 \\
\hline Resign & 31 & 11.7 \\
\hline Migration & 125 & 47.3 \\
\hline Total & 266 & 100.0 \\
\hline
\end{tabular}

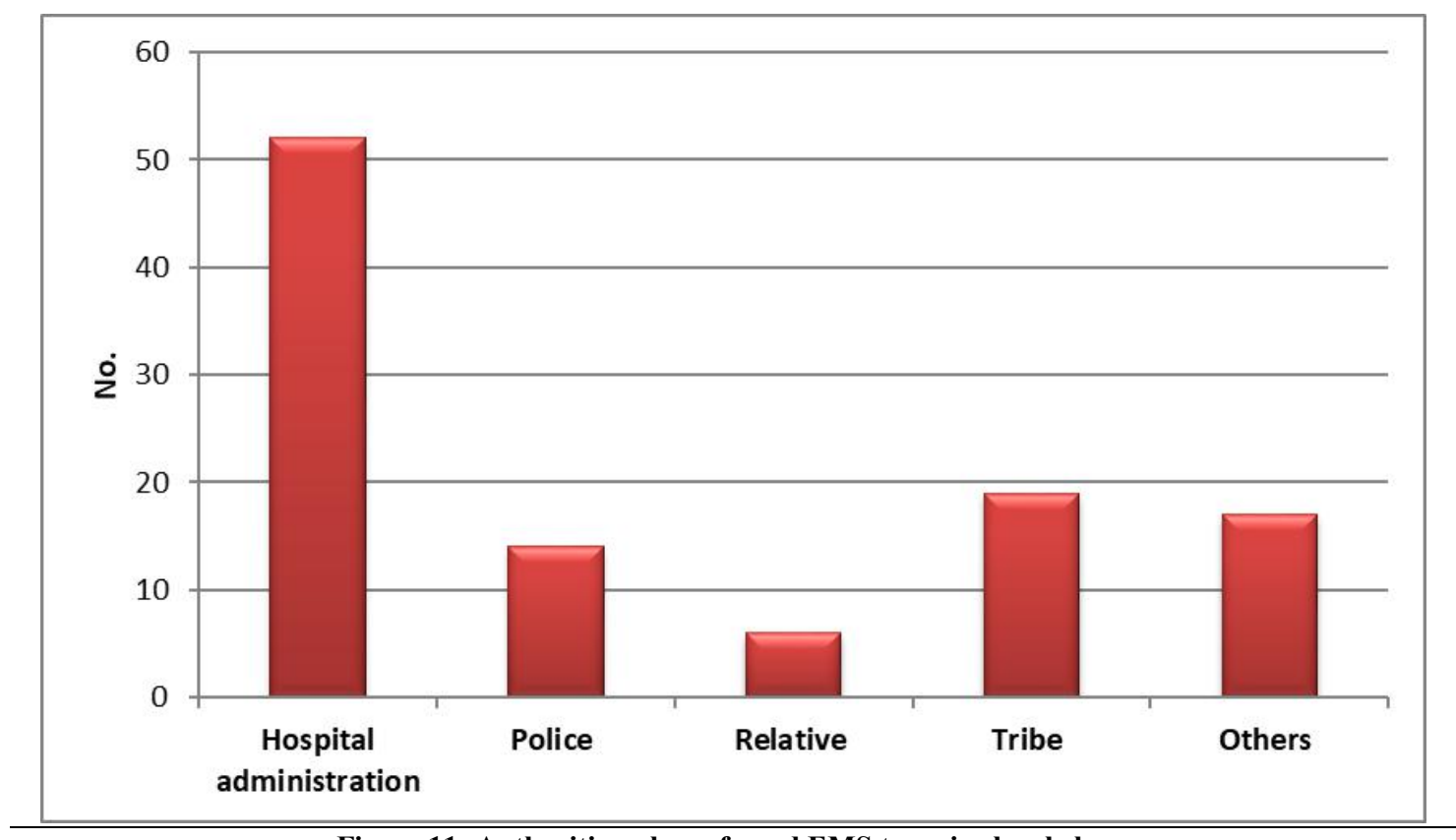

Figure 11: Authorities who enforced EMS to waive legal chase

Table 9: EMS recommendations regarding work place violence in ED

\begin{tabular}{|c|c|c|}
\hline \multicolumn{2}{|c|}{ Variable } & No. \\
\hline \multicolumn{2}{|c|}{ Recommendations of medical staff } \\
\hline Decreasing patients relatives & 293 & 14.8 \\
\hline Re-enforce security procedures & 285 & 14.4 \\
\hline $\begin{array}{c}\text { Increase human resources in each } \\
\text { department }\end{array}$ & 271 & 13.7 \\
\hline $\begin{array}{c}\text { Apply regular shift works } \\
\text { Lowering working duration } \\
\text { with patients }\end{array}$ & 204 & 10.3 \\
\hline $\begin{array}{c}\text { Training workshops in communication } \\
\text { public awareness on doctor role and } \\
\text { sionificance }\end{array}$ & 253 & 12.8 \\
\hline Activation of doctor protection \\
Other suggestions & 238 & 12.0 \\
\hline Total & 282 & 14.3 \\
\hline
\end{tabular}




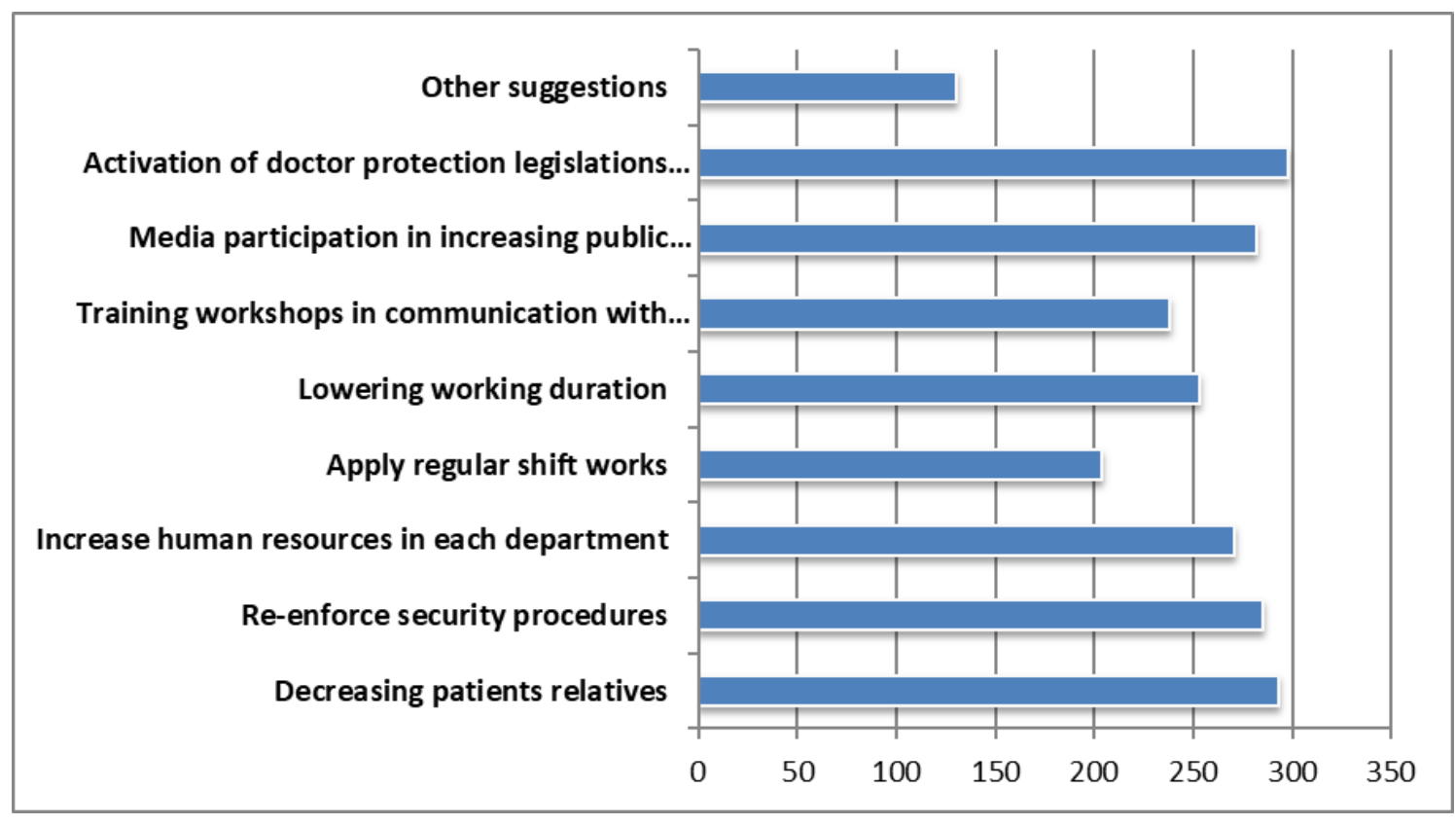

Figure 12: EMS recommendations

rising public health awareness coopertion of tribs lowering work time in ED protests increase medical staff number in ED more sympathy toward patients new doctor protection legislations punishing security forces changing national health system

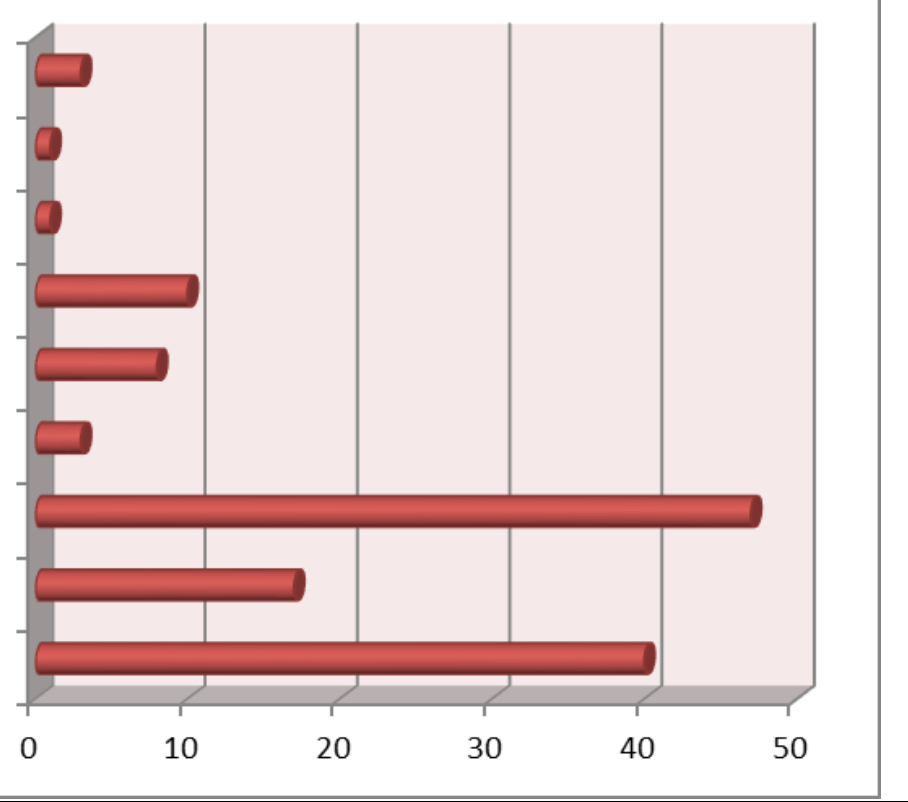

Figure 13: EMS suggestions 
Table 10: Distribution of EMS sociodemographic characteristics according to assault

\begin{tabular}{|c|c|c|c|c|c|c|}
\hline \multirow[t]{2}{*}{ Variable } & \multicolumn{2}{|c|}{ Assault } & \multicolumn{2}{|c|}{ No assault } & \multirow[t]{2}{*}{$\chi^{2}$} & \multirow[t]{2}{*}{$\mathbf{P}$} \\
\hline & No. & $\%$ & No. & $\%$ & & \\
\hline \multicolumn{5}{|c|}{ Age } & \multirow[t]{5}{*}{27.3} & \multirow[t]{5}{*}{$<0.001$} \\
\hline$<30$ years & 50 & 62.5 & 30 & 37.5 & & \\
\hline 30-39 years & 141 & 82.0 & 31 & 18.0 & & \\
\hline 40-49 years & 36 & 90.0 & 4 & 10.0 & & \\
\hline$\geq 50$ years & 2 & 25.0 & 6 & 75.0 & & \\
\hline \multicolumn{5}{|c|}{ Gender } & \multirow[t]{3}{*}{26.2} & \multirow[t]{3}{*}{$<0.001$} \\
\hline Male & 169 & 85.4 & 29 & 14.6 & & \\
\hline Female & 60 & 58.8 & 42 & 41.2 & & \\
\hline \multicolumn{5}{|c|}{ Residence } & \multirow[t]{3}{*}{0.6} & \multirow[t]{3}{*}{0.4} \\
\hline Inside Baghdad & 163 & 75.1 & 54 & 24.9 & & \\
\hline Outside Baghdad & 66 & 79.5 & 17 & 20.5 & & \\
\hline
\end{tabular}

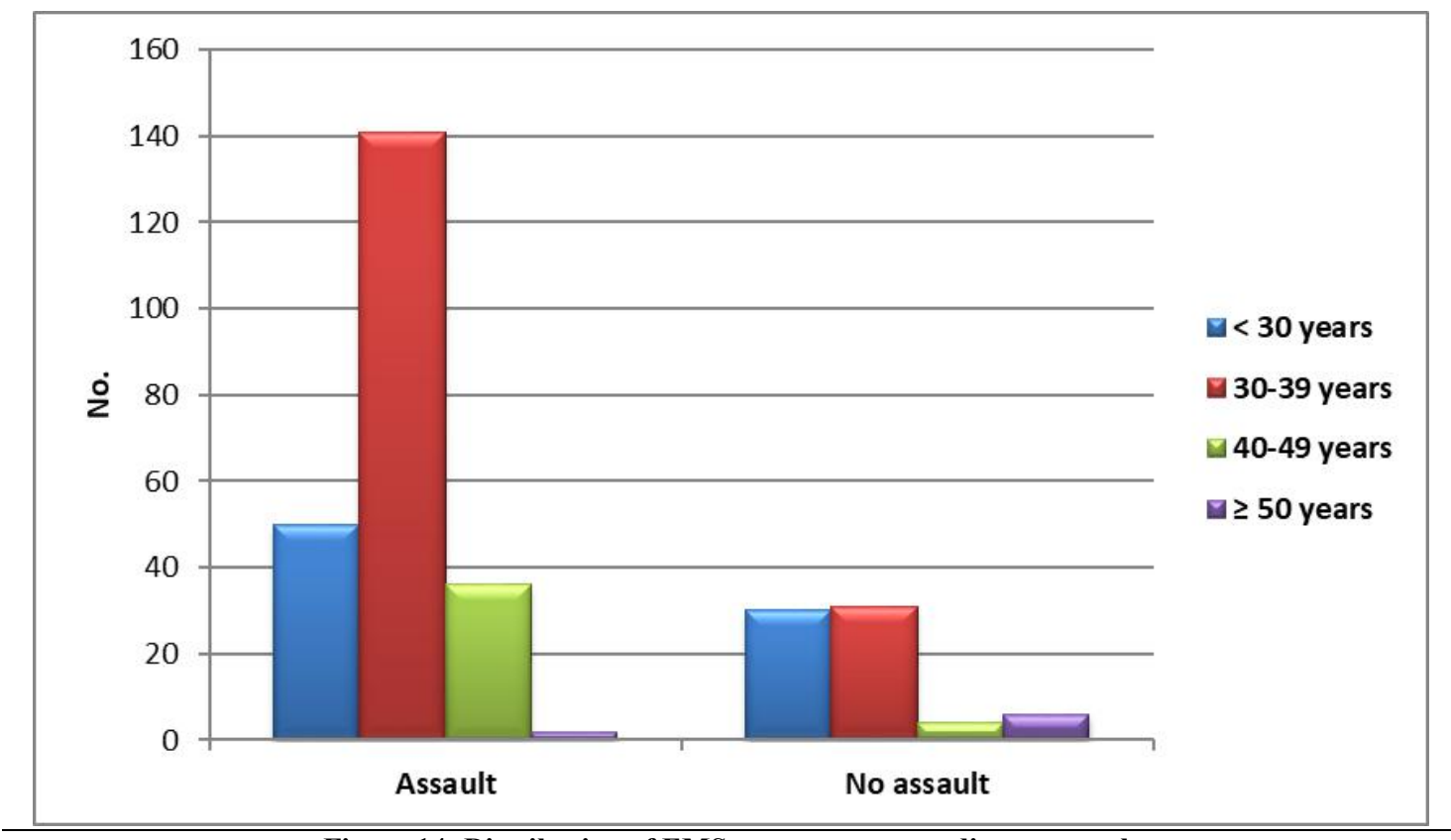

Figure 14: Distribution of EMS age groups according to assault 


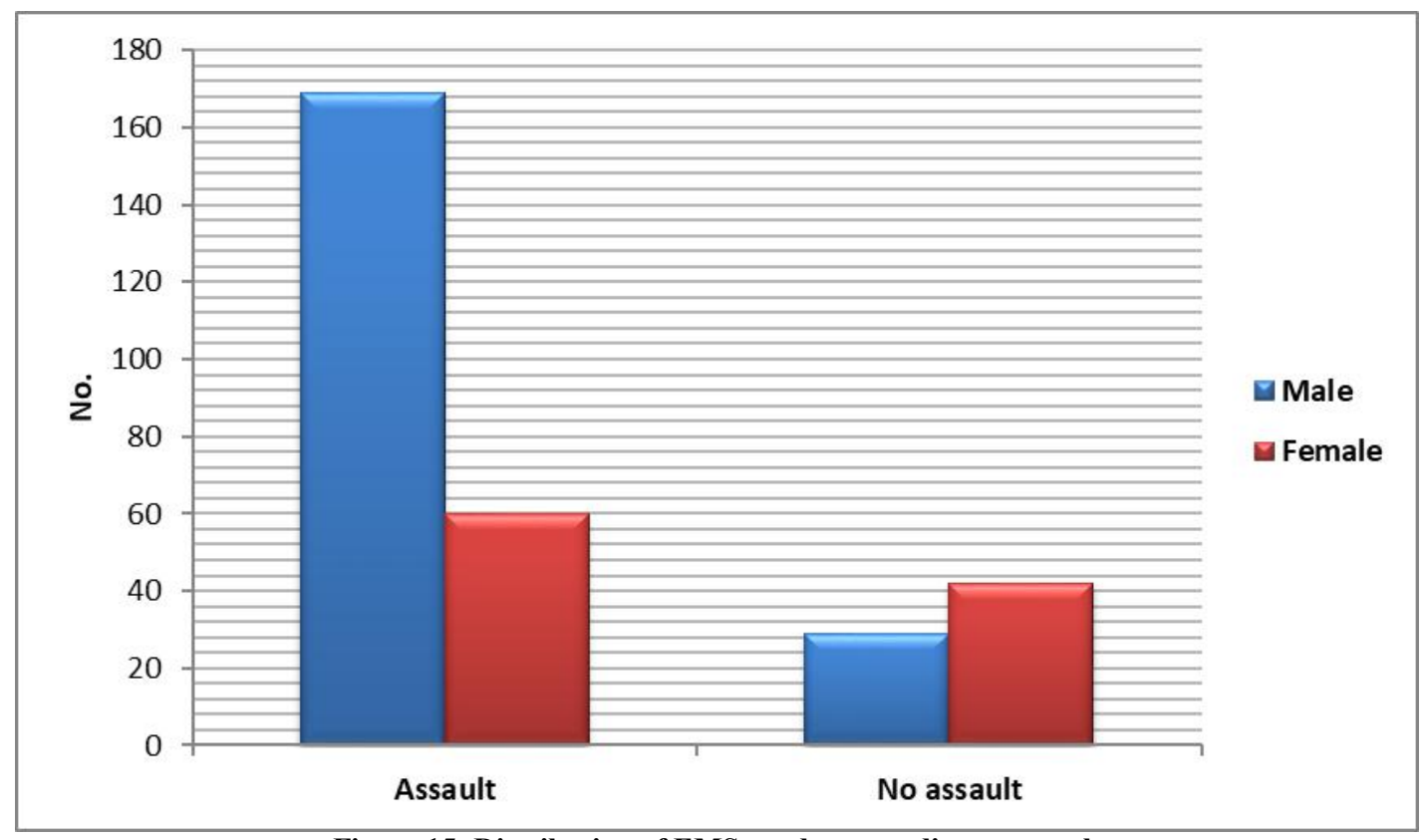

Figure 15: Distribution of EMS gender according to assault

Table 11: Distribution of EMS job characteristics according to assault

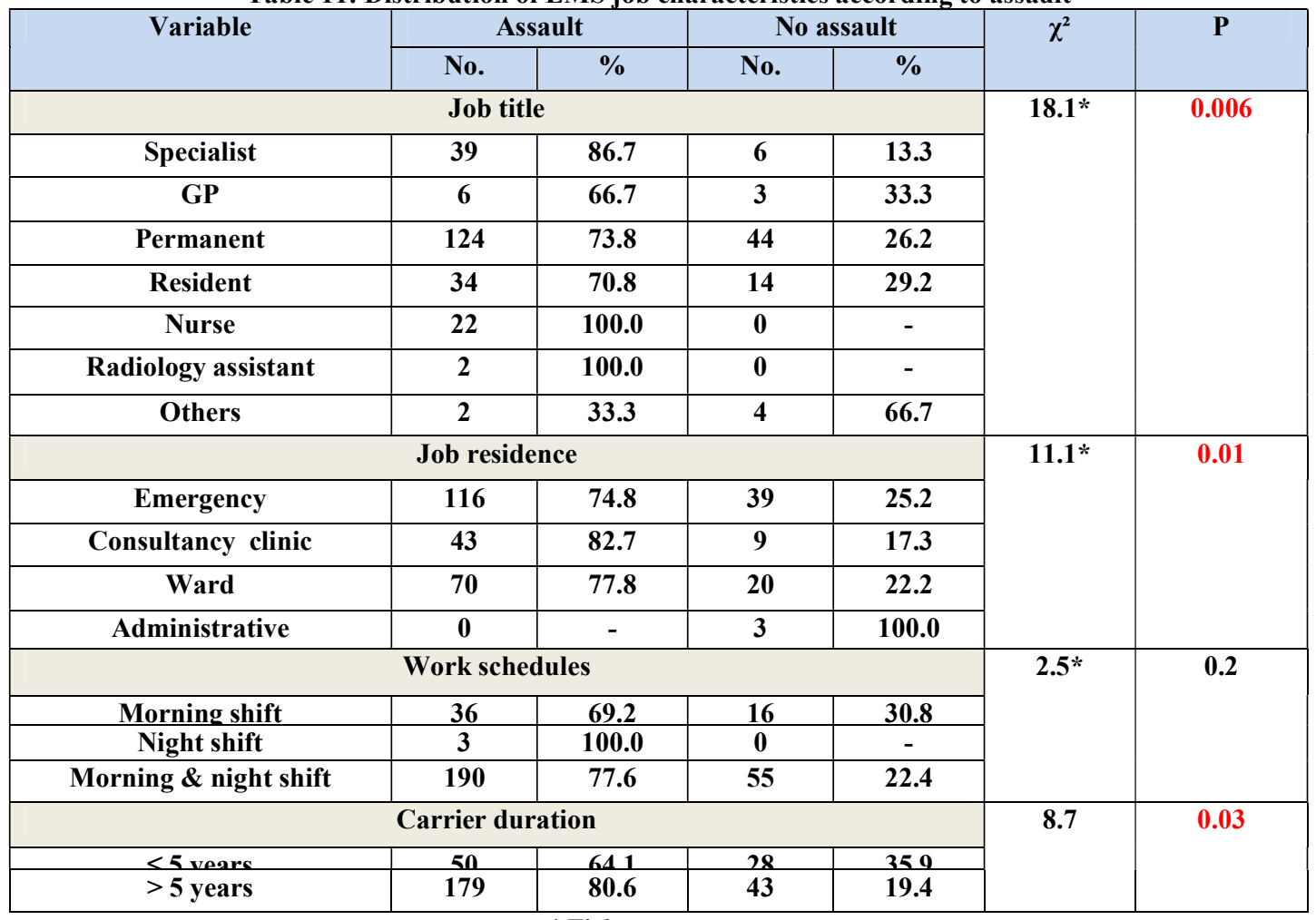

*Fishers exact test. 


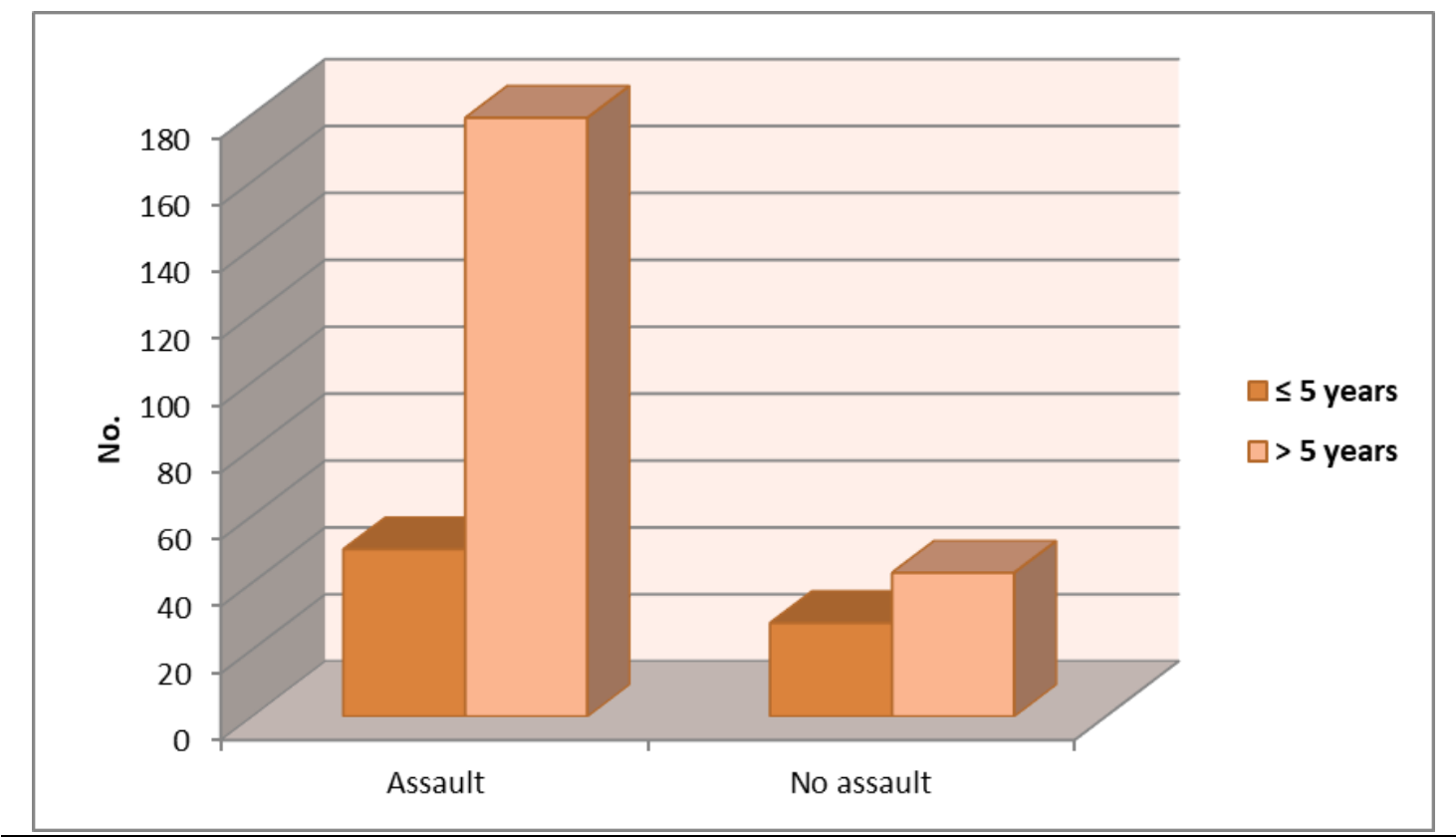

Figure 16: Distribution of EMS carrier duration according to assault

\section{DISCUSSION}

The violence is an unpleasant social incident that was uncontrolled by human being since the beginning of creation. Workplace Violence in emergency department is one of the important types of violence which the medical staff faced daily and range from harassment to physical attacks ${ }^{[46]}$. The WPV had many effects such as monetary, physical and psychological effects, in addition to environmental risks. Financial burden of WPV involve medical costs, staff recruitment and loss, health problems and patient security ${ }^{[47]}$.

In current study, the assault prevalence against medical staff in emergency department was $76.3 \%$. This finding is similar to results of previous Palestinian study ${ }^{[48]}$ that reported assault prevalence as $76.1 \%$ against medical staff in emergency department. The recorded assault prevalence by present study is close that reported by Iranian study ${ }^{[49]}$ as $75 \%$. Our finding regarding assault prevalence is lower than that reported by previous Turkey study ${ }^{[50]}$ which showed that the assault prevalence in emergency department of six general hospitals in Ankara was $85.2 \%$. This difference might be attributed to differences in culture and habits of societies in addition to fact that these reported studies measured the assault prevalence in last one year.

Present study showed that $73.4 \%$ of ED staff assaulted verbally and $7.4 \%$ of them 
were assaulted physically. This is close to results of Lebanon study [51] which conducted in ED of six tertiary hospitals revealed that in last 12 months $80 \%$ of ED employee had been verbally abused and $25 \%$ of ED employee was physically assaulted. Physical assault rate of $7.4 \%$ in this study is lower than that reported by French study ${ }^{[52]}$ as $40 \%$ although low prevalence of assault as $23 \%$ against medical staff in ED. This difference might be attributed to variation in violence level. In previous Iraqi study ${ }^{[53]}$ conducted in ED of Basra hospital, $48.7 \%$ of medical staff had faced verbal assault and $24.6 \%$ had faced physical assault. The verbal abuse had a destructive effect on medical staff working in ED as it disturbs staff away from patient care. Assaulted ED workers won't get their efficiency to normal level before assault even after long time, in addition to hazardous effect of verbal assault on other patients and their relatives who heard eruptions that lead to lack of perception and confidence and in turn poor quality of health care. However, many authors suggested high association of verbal assault with physical assault in ED ${ }^{[51]}$.
About two thirds of assaulters against medical staff in ED were patients' relatives. This finding is close to results of Iraqi study ${ }^{[53]}$ and Australian study ${ }^{[54]}$ which stated that most of the perpetrators in WPV occurred in ED were family members of the patients. Patients relatives and accompanying friends who make troubles in ED is a result of tribal behavior that is a characteristic of Iraqi community. These findings are consistent with results reported by studies in Jordan ${ }^{[55]}$, Turkey ${ }^{[56]}$, and the United States ${ }^{[57]}$. These unacceptable accidents need reenforcement of ED security infrastructure [58].

The main reasons for violence in ED as perceived by medical staff in present study were low health education of public and overcrowding of ED. These reasons are close to results of previous Iraqi study [59] which conducted in ED of Baquba Teaching hospital which showed that bad administration low public awareness are most reasons of WPV in ED. Cheraghi et al study in Iran ${ }^{[60]}$ revealed that most of assaulted nurses in ED perceived that overcrowding of ED is the common cause of assault. Emergency department workers might be able to predict the WPV before occurrence. About half of 
WPV accidents were related to alcohol or drugs intake, and violence onset in ED is always related to the social events in which these substances used, in addition to higher frequency of WPV during the evening shift and at holidays ${ }^{[61]}$.

The main response of ED medical staff at attack time was silence and the main reaction of them after the attack was upsetting and ignoring. This is consistent with results of previous studies carried out in Iraqi ${ }^{[53]}$ and Pakistan ${ }^{\text {[62]. These }}$ reactions are inconsistent with results of Iranian study [63] in which the main reaction of medical staff was asking the perpetrator to stop and reporting. This inconsistency might be due to large number of assaults against the medical staff without punishment discouraging the medical staff to resist. In more than half of assault cases the medical staff colleagues defended on them, but the problem was in about $30 \%$ of assault cases there was ignorance from the colleagues. This incident would leave a harmful effect on medical staff feelings and destruct the ethical relationship between colleagues ${ }^{[62]}$. Most of security men in ED ignored the assaults. This is similar to reports of USA study ${ }^{[64]}$ which stated that weak security procedures in emergency department are the main risk factor for WPV against medical staff. Weakness of security system in ED is related to influence of law in country ${ }^{[65]}$. Higher proportion of assaulted medical staff in present study did not report to hospital administration. This finding coincides with results of Turkish ${ }^{[50]}$ and Iranian ${ }^{[63]}$ studies. The main reason for not reporting as perceived by medical staff was it is useless. There is no constructed system for violence reporting in emergency department of Iraqi hospitals ${ }^{[66]}$. These results through light on high needs for training programs for reporting, preventing and managing violence in $\mathrm{ED}$, week application of laws and lack of appropriate reporting system. In previous Australian study two thirds of health care workers were satisfied with WPV control policies and reporting mechanisms [67]. This is attributed to presence of stable country political and economical status which in turn leads to transparent policies, good legislation, and reporting mechanisms in well developed countries ${ }^{63}$.

The ignorance and no reaction was the common response of all health authorities, media and parliament for assault cases in ED in our country. This 
finding is in agreement with results of previous Iraqi studies $[53,59,66]$ which discussed the violence against health workers in Iraq. Deterioration of security and political situations in Iraq in last decades is worsening the crises. About half of assaulted medical staff in ED was thinking seriously in migration. This is similar to Burnham et al ${ }^{68}$ study results which reported that violence in Iraq lead to migration of doctors; $3 \%$ due to threats, $0.67 \%$ due to kidnapping and 3.67 due to violent events. This migration thinking resulted in brain drain and loss of medical staff that the country learn, train for years and spent billions of dollars on them which leave a disastrous loss.

The main recommendation of medical staff to prevent violence in ED was the activation of doctor protection legislations in country. This legislation will decrease the WPV against health care workers as it constituted a deterrent to prevent the attacks and giving the health staff more confidence in their work ${ }^{[63,65]}$.

The assaults in this study were significantly associated with middle age male medical staff in ED. This finding is consistent with results of previous
Lebanese study [51]. However some authors revealed that female gender was the favorite gender for WPV in ED especially sexual harassment ${ }^{[61]}$.

The current study showed that permanent doctors, working in ED and long carrier duration of medical staff were significantly associated with high WPV in ED. These findings are in agreement with results of many studies in Iraq ${ }^{[66]}$, Australia ${ }^{[54]}$ and USA ${ }^{[57]}$. Permanent doctors worked for long periods in ED that exposing them for high assault cases in addition to their leadership role in ED.

\section{CONCLUSION}

The proportion of work place violence in emergency department of Baghdad hospitals in last six months is higher than previous literatures. The common violence type was verbal assault mainly done by patients' relatives with high frequency. The common reasons of work place violence as perceived by medical staff were low public awareness and overcrowding. Leaving work and migration were the main two responses of medical staff toward assaults. Ignorance was the main response of health authorities and media toward violence against health workers. 


\section{REFERENCES}

[1] Peek-Asa C, Casteel C, Allareddy V, Nocera M, Goldmacher S, Ohagan E, et al. Workplace violence prevention programs in psychiatric units and facilities. Arch Psychiatr Nurs. 2009; 23:166-176

[2] Farrell G, Cubit K. Nurses under threat: A comparison of content of 28 aggression management programs. Int $\mathrm{J}$ Ment Health Nurs $2005 ; 14: 44-53$.

[3] Taylor JL, Rew L. A systematic review of the literature: Workplace violence in the emergency department.J Clin Nurs 2011;20:1072-1085.

[4] St-Pierre I, Holmes D. Managing nurses through disciplinary power: A Foucauldian analysis of workplace violence. J Nurs Manag 2008; 16:352-359.

[5] Ray MM. The dark side of the job: Violence in the emergency department. J Emerg Nurs 2007; 33:257-261

[6] Gacki-Smith J, Juarez AM, Boyett L, Homeyer C, Robinson L, MacLean SL. Violence against nurses working in US emergency departments. J Nurs Adm 2009; 39:340-349.

[7]Zampieron A, Galeazzo M, Turra S, Buja A. Perceived aggression towards nurses: study in two Italian health institutions. J Clin Nurs 2010; 19(15-16):2329-2341.

[8] Hinchberger PA. Violence against female student nurses in the workplace. Nurs Forum 2009; 44(1):37-46.

[9] Chen WC, Hwu HG, Kung SM, Chiu HJ, Wang JD. Prevalence and determinants of workplace violence of health care workers in a psychiatric hospital in Taiwan. J Occup Health 2008; 50(3):288-293.

[10] Ünsal Atan Ş, Baysan Arabaci L, Sirin A, Isler A, Donmez S, Unsal Guler $\mathrm{M}$, et al. Violence experienced by nurses at six university hospitals in Turkey. Journal of psychiatric and mental health nursing 2013; 20(10):882889.

[11] Crilly J, Chaboyer W, Creedy D. Violence towards emergency department nurses by patients. Accid Emerg Nurs 2004; 12(2):6773.

[12] Taylor JL, Rew L. A systematic review of the literature: workplace violence in the emergency department. J Clin Nurs 2011; 20(7-8):1072-1085.

[13] Alameddine $\quad \mathrm{M}, \quad$ Yassin $\quad \mathrm{N}$. Addressing health workers' exposure to violence at Lebanese emergency departments: What do 
the stakeholders think? Journal of Hospital Administration 2013; 2(4):31-36.

[14] Farrell GA, Bobrowski C, Bobrowski P. Scoping workplace aggression in nursing: findings from an Australian study. J Adv Nurs 2006; 55(6):778-787.

[15] Boyle M, Koritsas S, Coles J, Stanley J. A pilot study of workplace violence towards paramedics. Emerg Med J 2007; 24(11):760-763.

[16] Al-Shaqsi S. Models of international emergency medical service (EMS) systems. Oman Medical Journal 2010; 25(4): 320. Available on: http://dx.doi.org/10.5001/omj.2010. $\underline{92}$

[17] Suserud BO, Blomquist M, Johansson I. Experiences of threats and violence in Swedish ambulance service. Prehospital and Disaster Medicine 2002; 17(S2): S84-S85. Available on: http://dx.doi.org/10.1017/S1049023 $\underline{\mathrm{X} 00011171}$

[18] Petzäll K, Tällberg J, Lundin T, Suserud B-O. Threats and violence in the Swedish pre-hospital emergency care. International Emergency Nursing 2011; 19(1): 511. Available on: http://dx.doi.org/10.1016/j.ienj.201 $\underline{0.01 .004}$

[19] Hahn M, Hantikainen K, Dassen H. Risk factors associated with patient and visitor violence in general hospitals: Results of a multiple regression analysis. International Journal of Nursing Studies 2013; 50(3): 374-385. Available on: http://dx.doi.org/10.1016/j.ijnurstu. $\underline{2012.09 .018}$

[20] Shahzad M. Workplace Violence: An Extensive Issue for Nurses in Pakistan: A Qualitative Investigation. Journal of Interpersonal Violence 2014; 5. Available on: http://dx.doi.org/10.1177/08862605 $\underline{13516005}$

[21] Gates DM, Gillespie GL, Succop P. Violence against nurses and its impact on stress and productivity. Nurs Econ 2011; 29(2): 59-66.

[22] DeKeseredy P. Advancing critical criminology: Theory and application. Lexington Books, Washington 2006.

[23] Carroll-Garrison MM. An exploration of managers' awareness and reaction to workplace incivility: A grounded theory study. University of Phoenix, USA 2012.

[24] U.S. Department of Labor Occupational Safety and Health 
Administration [OSHA], 2011.

OSHA fact sheet. Available on: http://www.osha.gov

[25] Richard J. Management of workplace violence victims. WHO 2013.violence. World Health Organization; 2003. Available on: http://www.who.int.

[26] Gacki-Smith J, Juarex A, Boyett L, Homeyer C, Robinson L, MacLean S. Violence against nurses working in us emergency departments. Journal of Nursing Administration 2009; 39(7): 340-349.

[27] Levin PF, Hewitt B, Misner T. Insights of nurses about assaults in hospital- based emergency departments. Image: Journal of Nursing Scholarship 2000; 30: 249254.

[28] Catlette M. A descriptive study of the perceptions of workplace violence and safety strategies of nurses working in level I trauma centers. Journal of Emergency Nursing 2005; 31: 519-525.

[29] Calabro K, Baraniuk S. Organizational factors related to safety in a psychiatric hospital. American Association of Occupational Health Nurses 2003; 51 (10): 425-432.

[30] May D, Grubbs L. The extent, nature and precipitating factors of nurse assault among three groups of registered nurses in a regional medical center. Journal of Emergency Nursing 2002; 28: 1117.

[31] Peek-asa C, Cubbin L, Hubbell K. Violent events and security programs in California emergency departments before and after the 1993 hospital security act. Journal of Emergency Nursing 2002; 28: 420-426.

[32] Kowalenko T, Walters B, Khare B, Compton S. Workplace violence: physicians in the state of Michigan. Annals of Emergency Medicine 2005; 46: 142-147.

[33] Brewer-Smyth， K. Preventing violence in the healthcare setting. Nursing Spectrum 2003. Available

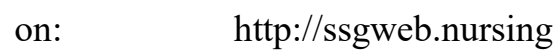
spectrum.com/ce/ce130.htm.

[34] Lee F. Violence in the A\&E: the role of training and self-efficacy. Nursing Standard 2001; 15: 33-38.

[35] Health Resources and Service Administration. The Registered Nurse Population: Findings from the National Sample Survey of Registered Nurses, 2004.Available on:

http://bhpr.hrsa.gov/healthworkforc e/reports/nursing/samplesurvey00/c hapter3.htm 
[36] Erickson L， Williams-Evans A. Attitudes of emergency nurses regarding patient assaults. Journal of Emergency Nursing 2000; 26: 210-215.

[37] Duxbury J, Whittington R. Causes and management of patient aggression and violence: Staff and patient perspectives. Journal of Advanced Nursing 2005; 50: 469478.

[38] Levin PF, Hewitt JB, Misner ST, Reynolds S. Assault of long-term care personnel Journal of Gerontelogical Nursing 2003; 29: 28-35.

[39] Nelson R. Tackling violence against health-care workers. Lancet 2014; 383: 1373-1374.

[40] O'Hanlon ME, Campbell JH. Iraq Index, Oct 1, 2007. The Brookings Institution. Available on: http://www.brookings.edu/fp/saban/ iraq/index.pdf

[41] Burnham GM, Lafta R, Doocy S. Doctors leaving 12 tertiary hospitals in Iraq, 2004-2007. Soc Sci Med 2009; 69: 172-177.

[42] Donaldson RI, Shanovich P, Shetty $P$, et al. A survey of national physicians working in an active confl ict zone: the challenges of emergency medical care in Iraq.
Prehosp Disaster Med 2012; 27: 153-161.

[43] Lafta M, Pandya A. Verbal and physical aggression against resident physicians in two general hospitals in Baghdad. J Musl Ment Hlth 2006; 1: 137-144.

[44] Doocy S, Malik S, Burnham G. Experiences of Iraqi doctors in Jordan during confl ict and factors associated with migration. Am J Disaster Med 2010; 5: 41-47.

[45] Abed AH. Violence against emergency care staff in Basra hospitals. International Journal of Medicine and Pharmaceutical Sciences 2014; 4 (2): 99-110.

[46] WHO, Di Martino V. Joint programme on workplace violence in the health sector. WHO 2003. ILO/ICN/WHO/PSI. Available on: http://www.who.int/violence injury prevention/violence/

[47] Roche M, Diers D, Duffield C, Catling-Paull C. Violence toward nurses, the work environment, and patient outcomes. Journal of Nursing Scholarship 2009; 42(1): 13-22.

[48] Hamdan M, Abu Hamra A. Workplace violence towards workers in the emergency departments of Palestinian hospitals: a cross-sectional study. 
Human Resources for Health. 2015; 13:28.

[49] Rahmani A, Hassankhani H, Mills J, Dadashzadeh A. Exposure of Iranian emergency medical technicians to workplace violence: a cross-sectional analysis. Emerg Med Australas 2012; 24(1):105110.

[50] Talas MS, Kocaöz S, Akgüç S. A survey of violence against staff working in the emergency department in ankara, Turkey. Asian Nurs Res (Korean Soc Nurs Sci) 2011; 5(4):197-203.

[51] Alameddine M, Kazzi A, El-Jardali F, Dimassi H, Maalouf $\quad$ S Occupational violence at Lebanese emergency departments: prevalence, characteristics and associated factors. J Occup Health 2011; 53(6):455-464.

[52] Duchateau FX, Bajolet-Laplante MF, Chollet C, Ricard-Hibon A, Marty J. Exposure of French emergency medical personnel to violence. Ann Fr Anesth Reanim 2002; 21(10):775-778.

[53] Abed AH. Violence against emergency care staff in Basra hospitals. International Journal of Medicine and Pharmaceutical Sciences 2014; 4 (2): 99-110.
[54] Mayhew C, Chappell D, the ILO/ICN/WHO/PSI Joint Programme on Workplace Violence in the Health Sector. Workplace Violence in the Health Sector -A Case Study in Australia. The Journal of Occupational Health and Safety - Australia and New Zealand 2003; 19(6): 354-387.

[55] Ahmad A. Verbal and physical abuse against Jordanian nurses in the work environment. Eastern Mediterranean Health Journal 2012; 18: 318-324.

[56] Celik SS, Celik Y, Agirbas I, Ugurluoglu O. Verbal and physical abuse against nurses in Turkey. International Nursing Review 2007; 54: 359-366.

[57] Nachreiner N, Hansen H, Okano A, Gerberich S, Ryan A, McGovern PM, et al. Difference in workrelated violence by nurse license type. Journal of Professional Nursing 2007; 23: 290-300.

[58] Darawad MW, Al-Hussami M, Saleh AM, Mustafa WM, Odeh $H$. Violence against nurses in emergency departments in jordan: nurses' perspective. Workplace Health Saf 2015; 63(1):9-17.

[59] Mahdi TS. Workplace Violence against Physicians and Health Care Providers in Baquba Teaching 
Hospital in 2014. A thesis submitted to college of medicineBaghdad University as requirement of Master degree, 2014.

[60] Cheraghi MA, Bahrani N, Javanmardi S, Akbari A, Zolfaghari M, Javanmardi Z. Predisposing Factors of Violence against Nurse in Emergency Department from Nurses', Patients', and accompanies' perspective. Medycyna pracy 2014; 23: 211222.

[61] Knott JC, Bennett D, Rawet J, Taylor DM. Epidemiology of unarmed threats in the emergency department. Emerg Med Australas 2005; 17: 351-358.

[62] Zafar W, Siddiqui E, Ejaz K, Shehzad MU, Khan UR, Jamali S, et al. Health care personnel and workplace violence in the emergency departments of a volatile metropolis: Results from Karachi, Pakistan. The Journal of emergency medicine. 2013; 45(5):761-772.

[63] Fallahi-Khoshknab M, Oskouie F, Najafi F, Ghazanfari N, Tamizi Z, Afshani S. Physical violence against health care workers: A nationwide study from Iran.Iranian
Journal of Nursing and Midwifery Research 2016; 21(3):232-238.

[64] Stene J, Larson E, Levy M, Dohlman M. Workplace Violence in the Emergency Department: Giving Staff the Tools and Support to Report. The Permanente Journal 2015; 19(2):e113-e117.

[65] Tabrizi JS, Gharibi F, Wilson AJ. Advantages and Disadvantages of Health Care Accreditation Models. Health Promotion Perspectives 2011; 1(1):1-31.

[66] AbuAlRub RF, Khalifa MF, Habbib MB. Workplace violence among Iraqi hospital nurses. J Nurs Scholarsh 2007; 39(3):281-288.

[67] Hegney D, Plank A, Parker V. Workplace violence in nursing in Queensland, Australia: A selfreported study. Int J Nurs Pract 2003; 9:261-268.

[68] Burnham GM, Lafta R, Doocy S. Doctors leaving 12 tertiary hospitals in Iraq, 2004-2007. Soc Sci Med 2009; 69(2):172-177. 